\title{
A GMMA-CPS-Based Vaccine for Non-Typhoidal Salmonella
}

\author{
Akosiererem S. Sokaribo 1,2, Sumudu R. Perera 1,2 ${ }^{1}$, Zoe Sereggela ${ }^{1,2}$, Ryan Krochak 1,2, Lindsay R. Balezantis ${ }^{1,2}$, \\ Xiaohui Xing ${ }^{3}$, Shirley Lam ${ }^{1}$, William Deck ${ }^{1}$, Sam Attah-Poku ${ }^{1}$, Dennis Wade Abbott ${ }^{3}$, Shantanu Tamuly ${ }^{4}$ \\ and Aaron P. White $1,2, *$ (D)
}

1 Vaccine and Infectious Disease Organization-International Vaccine Centre, Saskatoon, SK S7N5E3, Canada; ats172@mail.usask.ca (A.S.S.); sumudu.perera@usask.ca (S.R.P.); zhs569@mail.usask.ca (Z.S.); rdk945@mail.usask.ca (R.K.); lindsay.balezantis@usask.ca (L.R.B.); shirley.lam@usask.ca (S.L.); will.deck@usask.ca (W.D.); sam.attah-poku@usask.ca (S.A.-P.)

2 Department of Biochemistry, Microbiology and Immunology, University of Saskatchewan, Saskatoon, SK S7N5E5, Canada

3 Agriculture and Agri-Food Canada, Lethbridge Research and Development Centre, Lethbridge, AB T1J4B1, Canada; xiaohui.xing@canada.ca (X.X.); wade.abbott@canada.ca (D.W.A.)

4 Department of Veterinary Biochemistry, College of Veterinary Science, Assam Agricultural University, Khanapara, Guwahati 781022, Assam, India; shantanu.tamuly@aau.ac.in

* Correspondence: aaron.white@usask.ca; Tel.: +01-306-966-7485

check for updates

Citation: Sokaribo, A.S.; Perera, S.R.; Sereggela, Z.; Krochak, R.; Balezantis, L.R.; Xing, X.; Lam, S.; Deck, W.; Attah-Poku, S.; Abbott, D.W.; et al. A GMMA-CPS-Based Vaccine for Non-Typhoidal Salmonella. Vaccines 2021, 9, 165. https://doi.org/ $10.3390 /$ vaccines 9020165

Academic Editors: Ralph A. Tripp and Jason L. Larabee

Received: 13 November 2020 Accepted: 11 February 2021 Published: 17 February 2021

Publisher's Note: MDPI stays neutral with regard to jurisdictional claims in published maps and institutional affiliations.

Copyright: (C) 2021 by the authors. Licensee MDPI, Basel, Switzerland. This article is an open access article distributed under the terms and conditions of the Creative Commons Attribution (CC BY) license (https:// creativecommons.org/licenses/by/ $4.0 /)$.

\begin{abstract}
Non-typhoidal Salmonella are a major cause of gastroenteritis worldwide, as well as causing bloodstream infections in sub-Saharan Africa with a high fatality rate. No vaccine is currently available for human use. Current vaccine development strategies are focused on capsular polysaccharides (CPS) present on the surface of non-typhoidal Salmonella. This study aimed to boost the amount of CPS purified from S. Typhimurium for immunization trials. Random mutagenesis with Tn10 transposon increased the production of CPS colanic acid, by 10-fold compared to wildtype. Immunization with colanic acid or colanic acid conjugated to truncated glycoprotein D or inactivated diphtheria toxin did not induce a protective immune response in mice. However, immunization with Generalized Modules for Membrane Antigens (GMMAs) isolated from colanic acid overproducing isolates reduced Salmonella colonization in mice. Our results support the development of a GMMA-CPS-based vaccine against non-typhoidal Salmonella.
\end{abstract}

Keywords: vaccines; Salmonella; capsular polysaccharide; colanic acid; GMMAs

\section{Introduction}

Salmonella enterica species are the major cause of foodborne diseases, typhoid fever and gastroenteritis [1]. Typhoid fever, common in developing countries, is mainly caused by typhoidal Salmonella (TS) serovars: S. Typhi and S. Paratyphi [2]. Gastroenteritis occurs worldwide and is primarily caused by non-typhoidal Salmonella (NTS) serovars: $S$. Typhimurium and $S$. Enteritidis [2]. The global incidence of NTS gastroenteritis is estimated at $\sim 94$ million cases annually, with 155,000 deaths, and $~ 80.3$ million cases are contracted via foodborne transmissions [3]. NTS gastroenteritis is usually self-limiting in immunocompetent individuals and severe cases can be treated with antibiotics. However, there is an increase in multi-drug-resistant isolates [4], and in sub-Saharan Africa, NTS serovars associated with gastroenteritis globally are the leading cause of bloodstream infections that are distinct from typhoid fever [5,6]. A protective vaccine against NTS serovars and implementation of effective food safety procedures are needed to reduce the global incidence of gastroenteritis.

Capsular polysaccharides (CPS) are carbohydrate-based polymers synthesized and expressed on bacterial surfaces [7]. The CPS that have been identified in NTS are colanic acid, lipopolysaccharide (LPS) and O-Ag capsule [8-10]. Colanic acid composed of repeating units of glucose, galactose and fucose [8] is produced at temperatures below $30{ }^{\circ} \mathrm{C}$ 
and is thought to be involved in the survival of adverse environmental conditions [11,12]. LPS is the major component of the outer membrane of Gram-negative bacteria. It plays an important role in bacterial pathogenesis, and in the stimulation of an immune response [10]. $\mathrm{O}-\mathrm{Ag}$ capsule is a group IV CPS that has been implicated in Salmonella resistance to desiccation and killing by human immune serum $[9,13]$. Due to their surface location, CPS stimulate immune responses to bacteria and are optimal targets for vaccine development.

The LPS O-Ag is the target of protective immunity against NTS, however, the immune response is strain- or serovar-specific [14-16]. Since there are $>1500$ NTS serovars, a vaccine that can induce cross-protective immunity against the predominant NTS serovars will reduce the prevalence of gastroenteritis. The O-Ag capsule is an attractive vaccine candidate because it is comprised of tetrasaccharide repeating units of mannose, rhamnose, galactose and tyvelose or abequose, similar to LPS O-Ag [9,17]. Despite their similar repeating units, O-Ag capsule differs from LPS O-Ag in several ways: [1] O-Ag capsule is comprised of $>2000$ repeat units, while LPS O-Ag is comprised of $<100$ repeating units, [2] the tyvelose or abequose sugar in O-Ag capsule is glycosylated, [3] O-Ag capsule has a lower net charge and (4) O-Ag capsule is not associated with the LPS core region $[9,17]$. The increased molecular weight of oligosaccharides has been shown to result in improved immune response [18], and glycoconjugates from high molecular weight polysaccharides are immunogenic in humans at lower doses [19]. Due to the large number of repeating units, we hypothesized that immune response to O-Ag capsule could induce cross-protective immunity against the predominant NTS serovars that cause gastroenteritis.

Outer membrane vesicles (OMVs) are spherical outer membrane blebs spontaneously released by Gram-negative bacteria [20]. They are comprised of proteins, CPS and lipoproteins present on the outer membrane, and are released in all growth phases, and during infection $[20,21]$. OMVs are attractive vaccine candidates because they present antigens in their natural context to the immune system [20]. However, the amount of spontaneously released OMVs is not enough for vaccine development. Genetic modifications that disrupt the integrity of the inner and outer membrane have been shown to enhance OMV production $[22,23]$. OMVs released from genetically modified bacteria are called Generalized Modules for Membrane Antigens (GMMAs) [24]. GMMAs are desirable targets for the development of subunit vaccines because they lack the ability to cause disease, can deliver heterologous antigens [25,26] and are immunogenic [27]. Proteomic analysis has shown that GMMAs contain over 100 outer membrane and periplasmic proteins [24,28]. Due to the large number of antigens that GMMAs can present to the immune systems, GMMAs are being exploited for the development of cross-protective vaccines, for diseases like gastroenteritis caused by several NTS serovars [29].

In this study, we describe conditions that improve CPS production in S. Typhimurium. We also show how random mutagenesis aimed at increasing the production of O-Ag capsules for vaccine development led to increased colanic acid production. Immunization with colanic acid did not induce a protective immune response against S. Typhimurium. However, immunization with GMMAs purified from colanic acid overproducing Salmonella reduced bacterial colonization in mice.

\section{Materials and Methods}

\subsection{Bacterial Strains, Media and Growth Conditions}

The bacterial strains used in this study are listed in Table 1. For standard growth, strains were inoculated from frozen stocks onto LB agar (lysogeny broth, $1 \% \mathrm{NaCl}, 1.5 \%$ agar) supplemented with an appropriate antibiotic $(50 \mu \mathrm{g} / \mathrm{mL}$ kanamycin (Kan), $34 \mu \mathrm{g} / \mathrm{mL}$ chloramphenicol (Cam) or $5 \mu \mathrm{g} / \mathrm{mL}$ tetracycline (Tet)) and grown overnight at $37^{\circ} \mathrm{C}$. Isolated colonies were used to inoculate $5 \mathrm{~mL} \mathrm{LB}$ broth and the culture was incubated for 18 hours at $37^{\circ} \mathrm{C}$ with agitation at $200 \mathrm{rpm}$. For EPS purification, overnight cultures were grown for 5 days at $28{ }^{\circ} \mathrm{C}$ on agar supplemented with $1 \%$ glucose, $0.05 \%$ yeast extract, $10 \mathrm{mM} \mathrm{Na}_{2} \mathrm{HPO}_{4}, 0.1 \% \mathrm{NH}_{4} \mathrm{Cl}, 0.3 \% \mathrm{KH}_{2} \mathrm{PO}_{4}$, with or without $40 \mathrm{mM}$ MOPS (3-(N-morpholino)propanesulfonic acid). For murine infection experiments, overnight 
cultures grown in LB broth were diluted to the desired CFU concentration in $100 \mathrm{mM}$ HEPES (4-(2-hydroxyethyl)-1-piperazineethanesulfonic acid), $\mathrm{pH}$ 8, and used to infect mice.

Table 1. Strains and plasmids used in this study.

\begin{tabular}{|c|c|c|}
\hline Strains or Plasmids & Genotype & $\begin{array}{l}\text { Source or } \\
\text { Reference }\end{array}$ \\
\hline \multicolumn{3}{|l|}{ Strains } \\
\hline \multicolumn{3}{|l|}{ S. Typhimurium LT2 } \\
\hline TT10423 & proAB47/F' pro(+) lac(+) zzf-1831::Tn10(del) 16 (del) 17 & {$[30]$} \\
\hline S. Typhimurium 14028 & Wild-type strain & ATCC \\
\hline$\Delta b \operatorname{cs} A$ & Deletion of $b c s A$ ORF & [31] \\
\hline$\Delta y i h V W$ & Deletion of yihVW operon & This study \\
\hline$\Delta y i h W$ & Deletion of yihW ORF & This study \\
\hline$\Delta y i h$ & Deletion of yihUTSRQPO and yihVW operons & This study \\
\hline$\Delta b c s A \Delta y i h W$ & Deletion of $b c s A$ and yihW ORF & This study \\
\hline$\Delta w c a J$ & Deletion of wcaJ ORF & This study \\
\hline Tn10A & Tn10dtet insertion in Tnp IS200 & This study \\
\hline $\operatorname{Tn} 10 \mathrm{~B}$ & Tn10dtet insertion in filD & This study \\
\hline $\operatorname{Tn} 10 \mathrm{C}$ & Tn10dtet insertion in $s r f A$ & This study \\
\hline Tn10D & Tn10dtet insertion in stm14_2260 & This study \\
\hline Tn10E & Tn10dtet insertion in fhlA & This study \\
\hline Tn10F & Tn10dtet insertion in ompS & This study \\
\hline Tn10G & Tn10dtet insertion in stm14_3662 & This study \\
\hline $\operatorname{Tn} 10 \mathrm{C} \Delta$ tolR & Tn10dtet insertion in $s r f A$ and deletion of tolR ORF & This study \\
\hline$\Delta$ tolR & Deletion of tolR ORF & This study \\
\hline$\Delta l o n \Delta t o l R$ & Deletion of lon and tolR ORF & This study \\
\hline \multicolumn{3}{|l|}{ Plasmids } \\
\hline pNK972 & pBR322 derived plasmid with Tn10 transposase gene & [32] \\
\hline pBR322/yihVW & yihVW from S. Typhimurium 14028 & This study \\
\hline pCS26 & Bacterial luciferase & [33] \\
\hline pCS26-yihUTSRQPO & yihU promoter & [9] \\
\hline pCS26-yihVW & yih $V W$ promoter & [9] \\
\hline
\end{tabular}

For bioluminescence assays, overnight cultures of $S$. Typhimurium transformed with promoter luciferase fusions (yihUTSRQPO::luxCDABE or yihVW::luxCDABE), were diluted 1 in 600 in $1 \%$ tryptone broth supplemented with $50 \mu \mathrm{g} / \mathrm{mL}$ Kan to a final volume of $150 \mu \mathrm{L}$ in 96-well clear-bottom black plates (9520 costar Corning Inc) and overlaid with $50 \mu \mathrm{L}$ of mineral oil. Cultures were assayed for luminescence ( $1 \mathrm{~s}$; in counts per second (cps)) and absorbance $(590 \mathrm{~nm}, 0.1 \mathrm{~s})$ every $30 \mathrm{~min}$ during growth at $28^{\circ} \mathrm{C}$, with agitation in a Victor X3 multilabel plate reader (Perkin-Elmer, Waltham, MS, USA).

\subsection{Generation of S. Typhimurium Mutant Strains}

The lambda red recombinase knockout procedure [34] was used to generate $S$. Typhimurium $\Delta l o n, \Delta t o l R, \Delta y i h W, \Delta y i h$ and $\Delta y i h V W$ mutants. Primers containing 50-nucleotide sequences on either side of lon, tolR, yih, yihW or yihVW (Table 2) were used to amplify the cat gene from $\mathrm{pKD} 3$ or kan gene from pKD13 using Phusion High-Fidelity DNA polymerase (New England Biolabs, Ipswich, MS, USA). The PCR products were purified and electroporated into $S$. Typhimurium 14028 cells containing pKD46. Mutants were selected by growth at $37^{\circ} \mathrm{C}$ on LB agar supplemented with $10 \mu \mathrm{g} / \mathrm{mL}$ Cam or $50 \mu \mathrm{g} / \mathrm{mL}$ Kan. $\mathrm{Cam}^{\mathrm{R}}$ isolates were re-streaked onto LB agar containing $34 \mu \mathrm{g} / \mathrm{mL}$ Cam. Mutations were transduced into $S$. Typhimurium strains with a clean background using P22 phage [35]. The cat or kan gene was resolved from the chromosome using pCP20 [34]. DNA sequencing of PCR products from the chromosomes of mutant Salmonella isolates was used to verify the loss of lon, tolR, yih, yihW or yihVW. Primers used in this study are listed in Table 2. 
Table 2. Oligonucleotides used in this study.

\begin{tabular}{|c|c|c|}
\hline Primer & Sequence $\left(5^{\prime}-3^{\prime}\right)$ & Purpose \\
\hline yih operon F & $\begin{array}{c}\text { TTATTGGCCGGATAAAGCGCTGACGCGACC } \\
\text { CTCCGGCGCAAGGGCGCTTGGTGTAGGCTG } \\
\text { GAGCTGCTTC } \\
\text { AATATAGGGAAGCCGCCATCCATCGGGATG } \\
\text { GATAAAGCGGCAAGCGTCGTCCTCCTTAGT } \\
\text { TCCTATTCCG }\end{array}$ & $\begin{array}{l}\text { To amplify cat gene from pKD3 to generate } \Delta y i h \\
\text { strain by lambda-red recombination }\end{array}$ \\
\hline $\begin{array}{l}\text { yih operon PF } \\
\text { yih operon PR }\end{array}$ & $\begin{array}{c}\text { GGTTATAGGCCTCACGGTTT } \\
\text { TAATACGCGGTTAAAGTCGATGT }\end{array}$ & $\begin{array}{l}\text { To confirm deletion of yihUTSRQPO/yihVW } \\
\text { operons }\end{array}$ \\
\hline $\begin{array}{l}\text { yihVWkoFOR } \\
\text { yihVWkoREV }\end{array}$ & $\begin{array}{c}\text { TTCGTGAAATTAAAATGAGCACATCGAAAATGCT } \\
\text { TGAGGAATGACCATGGGTGTAGGCTGGAGCTGCTTC } \\
\text { TTGGCCGGATAAAGCGCTGACGCGACCCTCC } \\
\text { GGCGCAAGGGCGCTTGTCACCTCCTTAGTTCCTATTCCG }\end{array}$ & $\begin{array}{l}\text { To amplify cat gene product from pKD3 to generate } \\
\Delta y i h V W \text { strain by lambda-red recombination }\end{array}$ \\
\hline yihWkoFOR & $\begin{array}{l}\text { TAATATGAGCAGTAGGAAGCTTTTAGAGGA } \\
\text { ATGCTCATGAGTGTAGGCTGGAGCTGCTTC }\end{array}$ & Used with yihVWkoREV to generate $\Delta y i h W$ strain \\
\hline $\begin{array}{l}\text { yihVWdetect1 } \\
\text { yihVWdetect2 }\end{array}$ & $\begin{array}{l}\text { GCACATCGAAAATGCTTGAGGA } \\
\text { ATATCGCCTGCATCACAGCG }\end{array}$ & $\begin{array}{c}\text { To confirm the deletion of yihVW and yihW from } S . \\
\text { Typhimurium } 14028\end{array}$ \\
\hline $\begin{array}{l}\text { yihVWFOR } \\
\text { yihVWREV } \\
\text { yihVWseqF } \\
\text { yihVWseqR }\end{array}$ & $\begin{array}{c}\text { CGCGCTGCAGCTGTTTGTGATCGTATTTGTAATTTAT } \\
\text { GATCGACGTCGCATCACAGCGCCGTTTTATTG } \\
\text { GATCTTGCCGGGAAGCTAGAGTAAG } \\
\text { GATCTTCTTGAAGACGAAAGGGCCT }\end{array}$ & $\begin{array}{l}\text { Used to amplify yihVW from S. Typhimurium } \\
14028 \text { for cloning into pBR322. } \\
\text { To confirm the cloning of yihVW into pBR322 }\end{array}$ \\
\hline $\begin{array}{c}\text { TL } \\
\text { TR } \\
\text { ARB1 } \\
\text { ARB6 }\end{array}$ & $\begin{array}{c}\text { TCCATTGCTGTTGACAAAGGGAAT } \\
\text { ACCTTTGGTCACCAACGCTTTTCC } \\
\text { GGCCACGCGTCGANNNNNNNNGATAT } \\
\text { GGCCACGCGTCGANNNNNNNNACGCC }\end{array}$ & $\begin{array}{l}\text { Used for nested PCR (first reaction) to identify the } \\
\text { site of Tn10dtet insertion }\end{array}$ \\
\hline $\begin{array}{l}\text { Universal Tn } \\
\quad \text { ARB2 }\end{array}$ & $\begin{array}{l}\text { GACAAGATGTGTATCCACCTTAAC } \\
\text { GGCCACGCGTCGACTAGTAC }\end{array}$ & Used for nested PCR (second reaction) \\
\hline lonF & $\begin{array}{c}\text { CTATACTATCTGATTACCTGGCGGACACTAAACT } \\
\text { AAGAGAGAGCTCTATGATTCCGGGGATCCGTCGACC } \\
\text { TTATTAGCGCTATTTGCGCGAGGTCACTATTT }\end{array}$ & $\begin{array}{l}\text { To amplify kan gene product from } \mathrm{pKD} 13 \text { to } \\
\text { generate } \Delta l o n \text { strain by lambda-red recombination }\end{array}$ \\
\hline $\begin{array}{l}\text { lonPF } \\
\text { lonPR }\end{array}$ & $\begin{array}{l}\text { TGCGGTTACAACCTGCATTGTAGGCTGGAGCTGCTTCG } \\
\text { AACACGCCGTTGAATGTGTG } \\
\text { TTATATCAGGCCTGCCACGC }\end{array}$ & $\begin{array}{l}\text { To confirm the deletion of lon from } S \text {. } \\
\text { Typhimurium } 14028\end{array}$ \\
\hline wcaJ-ko-R & $\begin{array}{c}\text { ATCTCCCCTTACCGCCTGCGGGTAAGGGGCC } \\
\text { AATCACAGGAACAACGATGATTCCGGGGATC CGTCGACC } \\
\text { GTAAAATAGCCTTGTGGGTCAGGTTCTTAATA } \\
\text { CGCCGCTTTATTAACAAATGTAGGCTGGAGCTGCTTCG }\end{array}$ & $\begin{array}{l}\text { To amplify kan gene product from } \mathrm{pKD} 13 \text { to } \\
\text { generate } \Delta w c a J \text { strain by lambda-red } \\
\text { recombination }\end{array}$ \\
\hline $\begin{array}{l}\text { wcaJ-verF } \\
\text { wcaJ-verR }\end{array}$ & $\begin{array}{l}\text { CCAGAACCTGTTCACAAGGC } \\
\text { GCCTGAATGTGGAATCACGC }\end{array}$ & $\begin{array}{l}\text { To confirm the deletion of } w c a J \text { from } S \text {. } \\
\text { Typhimurium } 14028\end{array}$ \\
\hline TolR-ko_Rev & $\begin{array}{c}\text { TTCTGCACCGCCAGGCGTTTACCGTAAGCGA } \\
\text { AAGCAACAAGGGGTAAGCCGTGTAGGCTGGAGCTGCTTC } \\
\text { AAACTGTTCGCCTGTTACTCGCCGTCTTTCA } \\
\text { AGCCAACGGGACGCAGACTCCTCCTTAGTTCCTATTCCG }\end{array}$ & $\begin{array}{l}\text { To amplify cat gene product from } \mathrm{pDK} 3 \text { to generate } \\
\Delta \text { tolR strain by lambda-red recombination }\end{array}$ \\
\hline $\begin{array}{l}\text { TolR-F } \\
\text { TolR-R }\end{array}$ & $\begin{array}{l}\text { CTGCTCGACGTACTGTTG } \\
\text { ATCACCTGTTCAGACGGCAG }\end{array}$ & $\begin{array}{c}\text { To confirm the deletion of tolR from } S \text {. } \\
\text { Typhimurium } 14028\end{array}$ \\
\hline
\end{tabular}

\subsection{Generation of Transposon Mutants}

To generate $S$. Typhimurium $\triangle b c s A \Delta y i h W$ transposon mutants [30,32], $S$. Typhimurium LT2 harboring pNK972 was infected with P22 lysate of $S$. Typhimurium TT10423 containing Tn10dtet on $\mathrm{F}^{\prime}$. The resulting transductants $(\sim 100,000$ colonies) were pooled and a P22 $S$. Typhimurium LT2 Tn10dtet transducing fragment library was generated, following the method outlined by Maloy [35]. The resulting P22 phage lysate was used to infect $S$. Typhimurium $\triangle b c s A \Delta y i h W$ and plated on $1 \%$ tryptone supplemented with $10 \mu \mathrm{g} / \mathrm{mL}$ Tet. The resulting transductants $(10,000$ to 20,000$)$ were visually screened for the presence of a mucoid morphology, which was indicative of high CPS production. To identify the site of transposon insertion, nested PCR was performed on purified genomic DNA using primers TL or TR and ARB1 or ARB6. The product of the first reaction was further amplified using primers UniversalTn and ARB2. PCR products were purified and sequenced. To identify 
the site of Tn10 insertion, DNA sequence was mapped to $S$. Typhimurium 14028 using Geneious 9.0.5 (https:/ / www.geneious.com)

\subsection{Generation of Plasmid Vectors}

To generate pBR322-yihVW, the DNA region containing yihVW was PCR-amplified from $S$. Typhimurium 14028 genomic DNA using primers yihVWFOR and yihVWREV (Table 2) and Phusion polymerase (Thermo Fisher Scientific, Waltham, MS, USA), following reaction conditions as recommended by the manufacturer. The resulting PCR product was digested with AatII and PstI and ligated into AatII/PstI-digested pBR322 prior to electroporation into $S$. Typhimurium 14028. Positive clones were selected by growth on LB agar supplemented with $7 \mathrm{ug} \mathrm{mL}^{-1}$ Tet. The generation of pBR322-yihVW plasmid was confirmed by sequencing using primers yihVWseqF and yihVWseqR (Table 2). The generation of yihUTSRQPO and yihVW promoter region fused to luxCDABE operon has previously been described [9].

\subsection{Purification and Neutral Monosaccharide Analysis of Capsular Polysaccharide}

The capsular polysaccharide (CPS) purification protocol was adopted from Gibson et al. [9] with some modifications. To separate EPS from other cellular materials, $S$. Typhimurium cells scraped off the agar surface were resuspended in $1 \%$ phenol, mixed vigorously by vortexing and sedimented by centrifugation $\left(16,000 \times g, 4{ }^{\circ} \mathrm{C}, 4 \mathrm{~h}\right)$. Crude EPS was precipitated from the supernatant by adding 4 volumes of ice-cold acetone while stirring continuously with a glass rod. The resulting precipitate was stored overnight at $-20{ }^{\circ} \mathrm{C}$ to allow for further precipitation, sedimented by centrifugation $\left(6000 \times g, 4{ }^{\circ} \mathrm{C}\right.$, $15 \mathrm{~min}$ ) and air-dried. Crude EPS was resuspended in water, dialyzed in water for $48 \mathrm{~h}$ (MW cut-off $10 \mathrm{kDa}$; SnakeSkin dialysis tubing, Thermo Fisher Scientific) and lyophilized. The lyophilized polysaccharide was dissolved in buffer A ( $15 \mathrm{mM} \mathrm{NaOAc}, 0.05 \%$ Triton $\mathrm{X}-100, \mathrm{pH}$ 5.5) and $0.01 \%$ sodium azide. The dissolved sample was heated twice at $37^{\circ} \mathrm{C}$ for 15 min prior to loading onto $Q$ Sepharose FF xk50/11.5 and washing with 2 column volumes of buffer A. Materials were eluted with a stepwise gradient of buffer B (1.5 M NaOAc, $0.05 \%$ Triton X-100, pH 5.5), which was increased sequentially from $17 \%$ ( 1.25 column volumes) to $50 \%$ ( 1.25 column volumes) to $100 \%$ (1.5 column volumes). CPS-specific serum was used to identify fractions containing cross-reactive material by western blot.

For size exclusion chromatography, colanic acid containing fractions were pooled, concentrated (10 MWCO centrifuge filters, Amipore) and filtered through a $0.22 \mu \mathrm{m}$ syringe tip filter, prior to loading on to the Superdex S300 prep grad xk26/95 column. The column was washed with $50 \mathrm{mM} \mathrm{NH}_{4} \mathrm{HCO}_{2} \mathrm{pH}$ 7.72. Colanic acid containing fractions were identified using Western blot and concentrated with a Millipore Amicon Ultra-15 Centrifugal Filter Device, dialyzed in water for $48 \mathrm{~h}$ (MW cutoff $10 \mathrm{kDa}$; SnakeSkin dialysis tubing; Thermo Fisher Scientific) and lyophilized.

The dry polysaccharide samples were treated by thermostable $\alpha$-amylase and $\alpha$ glucosidase, followed by extensive dialysis against de-ionized water and freeze-drying to make sure the samples were glycogen-free [36]. The lyophilized samples were then hydrolyzed to monosaccharides by trifluoacetic acid, reduced with sodium borohydride, and acetylated using acetic anhydride [37]. The resulting alditol acetates were analyzed on an Agilent HP 5890 Series II gas chromatograph coupled to a flame ionization detector (GC-FID) fitted with a Rtx-2330 capillary column ( $15 \mathrm{~m}$ length $\times 0.32 \mathrm{~mm}$ internal diameter $\times 0.2 \mu \mathrm{m}$ film thickness; Restek Corporation). Inlet temperature was kept consistently at $250{ }^{\circ} \mathrm{C}$ and an injection volume of $1 \mu \mathrm{L}$ was used for all injections. For each sample run, the oven temperature was programmed to hold at $180^{\circ} \mathrm{C}$ for $2 \mathrm{~min}$, increase from 180 to $230{ }^{\circ} \mathrm{C}$ at $4{ }^{\circ} \mathrm{C} / \mathrm{min}$, from 230 to $260^{\circ} \mathrm{C}$ at $8^{\circ} \mathrm{C} / \mathrm{min}$, followed by holding at $260^{\circ} \mathrm{C}$ for $10 \mathrm{~min}$, and the inlet program was programmed to increase from 5.0 to $6.0 \mathrm{psi}$ at $0.10 \mathrm{psi} / \mathrm{min}$, from 6.0 to $7.0 \mathrm{psi}$ at $0.20 \mathrm{psi} / \mathrm{min}$ and from 7.0 to $8.0 \mathrm{psi}$ at $0.40 \mathrm{psi} / \mathrm{min}$, followed by holding at $8.0 \mathrm{psi}$ for $10.75 \mathrm{~min}$ (total run time $28.25 \mathrm{~min}$ ). Relative monosaccharide composition 
(mol\%) was calculated by referring to the FID responses of monosaccharide standards. Experiments were conducted in triplicate.

\subsection{Endotoxin Removal from Purified EPS}

For endotoxin removal by acid hydrolysis, purified crude EPS were dissolved in $1 \%$ acetic acid and heated in an oil bath at $110^{\circ} \mathrm{C}$ for $100 \mathrm{~min}$ [38]. The solution was centrifuged for $10 \mathrm{~min}$ at $8000 \mathrm{rpm}$. Pellet was discarded and the supernatant was lyophilized before colanic acid isolation using anion exchange and size exclusion chromatography.

For endotoxin removal using Triton X-114, purified colanic acid was dissolved in precondensed Triton X-114, prepared by dissolving $20 \mathrm{~mL}$ of Triton X-114 and $16 \mathrm{mg}$ of 2, 6-Ditert-butyl-4-methylphenol at $4{ }^{\circ} \mathrm{C}$ in $10 \mathrm{mM}$ Tris- $\mathrm{HCl}$ (pH 7.4), $150 \mathrm{mM} \mathrm{NaCl}$ solution [39]. The mixture was incubated at $30^{\circ} \mathrm{C}$ until it separated into a detergent-depleted aqueous phase and a detergent-rich phase. The large aqueous phase was discarded and replaced with an equal volume of $10 \mathrm{mM}$ Tris- $\mathrm{HCl}$ ( $\mathrm{pH} 7.4), 150 \mathrm{mM} \mathrm{NaCl}$. The solution was mixed and incubated at $30{ }^{\circ} \mathrm{C}$ to enable phase separation. After three rounds of phase separation, the detergent-rich phase with a Triton X-114 concentration of 11\%, was collected and stored at room temperature [38].

For endotoxin removal using pre-condensed Triton X-114, purified EPS was dissolved in water to a final concentration of $0.5 \mathrm{mg} / \mathrm{mL}$ and mixed with $11 \%$ Triton $\mathrm{X}-114$ to a final Triton X-114 concentration of $1 \%(w / v)$. The resulting cloudy solution was stirred for $30 \mathrm{~min}$ at $4{ }^{\circ} \mathrm{C}$ until the solution became clear. The mixture was incubated at $37^{\circ} \mathrm{C}$ for $30 \mathrm{~min}$ to induce separation into two phases, and subsequently centrifuged at $1200 \times g$ for $30 \mathrm{~min}$ at $25^{\circ} \mathrm{C}$. The lower phase containing LPS was discarded and the upper phase containing EPS was mixed with $11 \%$ Triton X-114 to a final concentration of $2 \%$. LPS extraction was repeated twice as described above. Centrifugation speed and time were increased by $1000 \times g$ and $30 \mathrm{~min}$ for each round of purification to obtain the best separation.

To remove detergent from the EPS-containing solution after LPS removal, the Triton X-114-treated samples were mixed with three volumes of methanol-chloroform (two volumes of methanol and one volume of chloroform) and incubated at room temperature for $30 \mathrm{~min}$ to enable phase separation. The Triton X-114 containing lower phase was eluted and the colanic acid containing upper phase was mixed again with the methanolchloroform solution. This procedure was repeated two additional times. Residual methanolchloroform was removed using water aspiration. Samples were dialyzed for $48 \mathrm{~h}$ in $\mathrm{ddH}_{2} \mathrm{O}$ at $4{ }^{\circ} \mathrm{C}$ and lyophilized.

\subsection{Conjugation of EPS to Truncated Glycoprotein D (tgD) and CRM197}

Twenty $\mathrm{mg}$ of purified colanic acid dissolved in $0.15 \mathrm{M} \mathrm{NaCl}$ (2 $\mathrm{mL}$ final volume) was allowed to react with $13 \mathrm{mg}$ of sodium cyanoborohydride $(\mathrm{CNBr}$, dissolved in $16 \mu \mathrm{L}$ chloroform), and the $\mathrm{pH}$ of the solution was maintained at $\mathrm{pH} 10.5$ using $\mathrm{NaOH}(0.5 \mathrm{M})$. After $15 \mathrm{~min}$ at room temperature, adipic dihydrazide (ADH) was added to a final concentration of $12 \mathrm{mg} / \mathrm{mL}$. $\mathrm{HCl}(0.5 \mathrm{M})$ was used to reduce the final $\mathrm{pH}$ to 8.5 . The reaction mixture was incubated at room temperature overnight with stirring. The solution was dialyzed twice against $20 \mathrm{mM}$ MES buffer ( $\mathrm{pH}$ 6.0) using a $10 \mathrm{kDa}$ cut-off MWCO dialysis tubing for 3 hours at $4{ }^{\circ} \mathrm{C}$ [40]. Inactivated diphtheria toxin CRM197 was obtained from Fina Biosolutions LLC (Rockville, MD, USA). The purification of truncated glycoprotein has been previously described [41].

The resulting CNBr-treated CPS $(5 \mathrm{mg} / \mathrm{mL}, 3 \mathrm{~mL})$ was allowed to react with $1.5 \mathrm{~mL}$ tGD or CRM197 $(2 \mathrm{mg} / \mathrm{mL}$ ) in the presence of $12 \mathrm{mg}$ EDC (dissolved in $20 \mathrm{mM}$ MES buffer $\mathrm{pH}$ 6.0) at room temperature overnight. The resulting solution was dialyzed against $0.15 \mathrm{M}$ $\mathrm{NaCl}$ using $10 \mathrm{kDa}$ MWCO dialysis tubing for $3 \mathrm{~h}$ at $4{ }^{\circ} \mathrm{C}$. CPS conjugated to tGD (CA-tgD) or CRM197 (CA-CRM197) was loaded onto a Sephacryl S300 xk26/94 column. The column was washed with $50 \mathrm{mM}$ PBS, $15 \mathrm{mM} \mathrm{NaCl}$, pH 7.4 solution and $10 \mathrm{~mL}$ fractions were collected. Fractions containing conjugated material were identified based on size after western blot analysis with EPS-specific serum. 


\subsection{Outer Membrane Vesicles (GMMAs) Production and Purification}

For GMMA production, bacteria grown overnight at $37{ }^{\circ} \mathrm{C}$ were used to inoculate $1 \%$ tryptone broth (without antibiotics) to an optical density of 0.03 at $600 \mathrm{~nm}$. Cultures were incubated at $30{ }^{\circ} \mathrm{C}$, for $18 \mathrm{~h}$ with agitation $(200 \mathrm{rpm}$ ). Culture supernatants were collected by centrifugation at $8000 \times g$ for $10 \mathrm{~min}$, filtrated with a $0.45 \mu \mathrm{m}$ filter, and concentrated by dialysis (MW cut-off $10 \mathrm{kDa}$; SnakeSkin dialysis tubing, Thermo Fisher Scientific) against polyethylene glycol (PEG) 2000. GMMAs were pelleted by ultra-centrifugation at $186,000 \times g$ for $2 \mathrm{~h}$ at $4{ }^{\circ} \mathrm{C}$. The resulting pellets were resuspended in endotoxin-free water, filtered with a $0.22 \mu \mathrm{m}$ filter, lyophilized, and resuspended in PBS.

\subsection{Vaccine Formulation}

Vaccine antigens, colanic acid (CA), CA-tgD and CA-CRM197 were formulated with triple combination adjuvant consisting of Polyinosinic:polycytidylic acid (Poly (I:C)) (Thermo Fisher Scientific), host defense peptide (HDP) and polyphosphazene (PCEP) (Idaho National laboratory) immediately prior to administration. Formulations were prepared by first mixing $10 \mu \mathrm{g}$ of PIC and $20 \mu \mathrm{g}$ HDP in PBS and incubating at room temperature (RT) for $15 \mathrm{~min}$. CA, CA-tgD or CA-CRM197 were added before the addition of $10 \mu \mathrm{g}$ of PCEP, making a final ratio of 1:2:1 of PIC:HDP:PCEP (TriAdj). Mixtures were incubated in the dark for $15 \mathrm{~min}$ at RT prior to administration.

\subsection{Murine Immunization Experiments}

Six- to eight-week-old female BALB/c mice were purchased from Charles River Laboratories (Kingston, ON), while C57BL/ 6 mice were purchased from Jackson Laboratory (Bar Harbor, ME). Mice were assigned to cage groups using a randomization table prepared in Microsoft Excel and individual mice were marked with ear notches.

Two groups of six BALB/C mice were immunized intramuscularly 3 times at 2-week intervals with $50 \mu \mathrm{g}$ colanic acid (CA), $1 \mu \mathrm{g}$ CA conjugated to tGD (CA-tGD), or phosphatebuffered saline (PBS). Serum was collected on days $0,15,29,43$ and 58. Three groups of six C57BL/ 6 mice were immunized intramuscularly 2 times at 3-week intervals with $50 \mu \mathrm{g}$ CA, $50 \mu \mathrm{g}$ CA conjugated inactivated diphtheria toxin (CA-CRM197), or PBS. Serum was collected on days $0,21,42$ and 63 .

For immunization with GMMAs, four groups of six C57BL/ 6 mice were immunized intramuscularly with PBS or $50 \mu$ g of GMMAs purified from $S$. Typhimurium $\Delta t o l R$ (STmGMMA), S. Typhimurium $\Delta$ lon $\Delta$ tolR (lon-GMMA), or $S$. Typhimurium $\Delta b c s A \Delta y i h W \Delta t o l R$ Tn10C (Tn10C-GMMA). Secondary and tertiary immunizations were performed with $5 \mu \mathrm{g}$ of GMMAs at three-week intervals. Serum samples were collected on days 0, 21, 42 and 63 .

\subsection{Murine Infection Experiments}

For competitive index (CI) experiments, two groups of six C57BL/ 6 mice were challenged with a mixed inoculum consisting of 1:1 ratio of $\operatorname{Kan}^{\mathrm{R}}$ and $\mathrm{Cam}^{\mathrm{R}} S$. Typhimurium 14028 strains containing the sig70_16 luxCDABE construct [42]. Mice were challenged via oral gavage with a total $\mathrm{CFU}$ of $\sim 10^{7}$.

Immunized C57BL/ 6 or BALB/C mice were challenged 21 days after the final immunization by oral gavage with $10^{7} \mathrm{CFU}$ of $\mathrm{Kan}^{\mathrm{R}} \mathrm{S}$. Typhimurium containing the sig70_16 lux $C D A B E$ construct.

Infected mice were weighed daily and monitored for clinical signs of infection. Mice that had a $>20 \%$ drop in weight were humanely euthanized. All mice were humanely euthanized 4-7 days post-infection. Spleen, liver, mesenteric lymph nodes (MLN) and cecum were collected from each mouse. Blood was collected from C57BL/6 mice.

Collected organs were placed in a $2 \mathrm{~mL}$ Eppendorf Safe-Lock tube containing $1 \mathrm{~mL}$ of phosphate-buffered saline (PBS) and a $5 \mathrm{~mm}$ steel bead (Product\# 69989; Qiagen, Hilden, Germany) and homogenized using a mixer mill (MM400; Retsch Gmbh, Haan, Germany) for $5 \mathrm{~min}$ at $30 \mathrm{~Hz}$. Serial dilutions of organ homogenates and blood were plated on LB agar supplemented with $50 \mu \mathrm{g} / \mathrm{mL}$ Kan and the number of Salmonella CFU were 
enumerated. Organs collected from mice infected with a mixed inoculum were plated on both Kan and Cam agar. The CI values were calculated as follows: (CFU mutant/CFU wildtype $)_{\text {output }} /(\mathrm{CFU} \text { mutant/CFU wildtype })_{\text {input }}$.

\subsection{ELISA}

Serum IgG levels specific for CA, tgD, CRM197 and GMMAs were measured by ELISA. Briefly, 96-well plates were coated with CA ( $2 \mu \mathrm{g}$ per well), tgD, CRM197 or GMMA $\left(0.1 \mu \mathrm{g}\right.$ per well) in coating buffer at $4{ }^{\circ} \mathrm{C}$ overnight. Wells were blocked for $30 \mathrm{~min}$ at RT with 5\% skim milk dissolved in Tris-buffered saline (TBS) containing 0.05\% tween 20 (TBST). Sera were serially diluted in TBST, starting at 1:100 in 5-fold dilutions. Alkaline phosphatase-conjugated goat-anti-mouse IgG at a dilution of 1:1500 was used to detect bound IgG. The reaction was visualized with p-nitrophenyl phosphate, and absorbance was read at $405 \mathrm{~nm}$ with a reference wavelength of $409 \mathrm{~nm}$.

\subsection{Statistical Analysis}

Statistical analyses were performed using GraphPad Prism version 8.0.0 for Mac OS (GraphPad Software, San Diego, CA, USA).

The normality of all datasets was assessed using the Shapiro-Wilk normality test. For luciferase assays, if the data were not normally distributed, comparisons were made using the Mann-Whitney test. If data were normally distributed, comparisons were made using the unpaired $t$-test.

For murine infections, if the data were normally distributed, comparisons were performed using unpaired $t$-test with Welch's corrections. If any data sets were not normally distributed, comparisons were performed using the Mann-Whitney test.

For CI experiments, if the data were normally distributed, a one-sample $t$-test was used to determine if the mean was significantly different from one. If the data were not normally distributed, the Wilcoxon signed-rank test was used to determine if the median CI was significantly different from one.

\section{Results}

\subsection{The yih Operons Are Not Involved in S. Typhimurium Virulence}

The divergently transcribed yihUTSRQPO (yihU) and yihVW operons have been identified as the operons controlling O-Ag capsule biosynthesis in Salmonella [9]. Using bioluminescence, White et al. [43] showed that the yih $U$ operon is expressed during infection. Since virulence factors are often optimal vaccine candidates, we wanted to determine if the yih operons are involved in Salmonella virulence. We performed a competitive index experiment in C57BL/ 6 mice orally challenged with a 1:1 mixture of $S$. Typhimurium 14028 (wildtype) and $S$. Typhimurium $14028 \Delta$ yih. At $4-7$ days post-infection, mice were euthanized and bacterial loads in the spleen, liver, MLN and cecum were enumerated. An equal number of wildtype and S. Typhimurium 14028 $\Delta$ yih were recovered from all organs tested (Figure 1), suggesting that the yih operons are not involved in Salmonella virulence.

\subsection{YihW Represses Expression of the Yih Operons}

One of the problems of commercializing CPS-based vaccines is the difficulty to produce large quantities of CPS at an industrial scale. Therefore, our first objective was to boost O-Ag capsule production in Salmonella serovar Typhimurium by increasing the expression of the yih operons. It is often difficult and inefficient to purify CPS in the presence of cellulose because it non-specifically binds the materials in the extracellular matrix [31]. Therefore, a cellulose-negative strain was used for Salmonella CPS purification.

Genes in the yihUTSRQPO operon are homologous to carbohydrate metabolism genes, while genes in the yihVW operon are homologous to regulatory genes (yih $V$ have homology to kinases, while yihW has homology to glycerol-3-P regulon repressor) [9]. To determine if genes in the yihVW operon have a regulatory effect on the expression of the yih operons, yihUTSRQPO and yihVW promoter::lux fusions were used to measure the promoter activity 
of both operons in $S$. Typhimurium. Deletion of cellulose synthase $(\triangle b c s A)$ had no effect on the expression of yihU (Figure 2A), and increased yihVW expression by $\sim 70$-fold (Figure $2 \mathrm{~B}$ ). Plasmid-based overexpression of yihVW had no effect on yihVW expression but reduced yih $U$ expression by $\sim 20$-fold. Deletion of yihVW or yihW alone increased yih $U$ expression by $\sim 100$-fold (Figure 2A). Our results are consistent with YihW being a transcriptional repressor of the yihUTSRQPO operon.

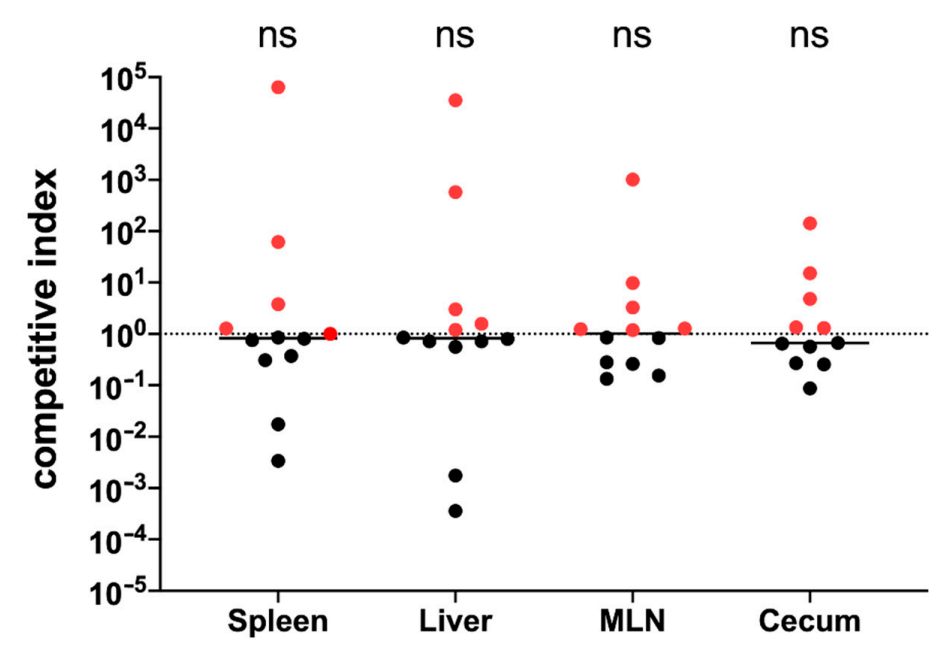

Figure 1. Evaluating the role of yih operon in the virulence of $S$. Typhimurium. A competitive index experiment was performed with C57BL/ 6 mice orally infected with wildtype and $S$. Typhimurium $14028 \Delta y$ ih. At 4-7 days post-infection, the CFU levels were enumerated from the liver, spleen, cecum and MLN. Each dot represents the CFU counts (per organ) from the designated organ from a single mouse. Competitive index values were calculated from each organ as follows: (CFU yih mutant/ $w t)_{\text {output }} /(\mathrm{CFU} \text { yih/wt })_{\text {input }}$. A CI value of 1 , which represents a situation where both strains are equally virulent, is represented by the horizontal dotted line. Red circles represent CI values where the S. Typhimurium $14028 \Delta$ yih strain won the competition. Statistical differences between groups of mice were noted as ns: $p>0.05$.

\section{yihU::luxCDABE}

A

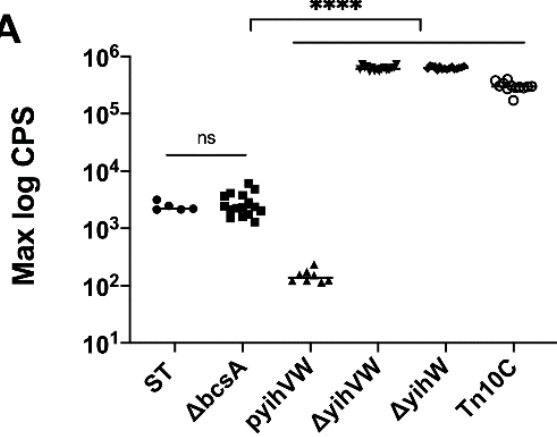

Strains
yihVW::IuxCDABE

B

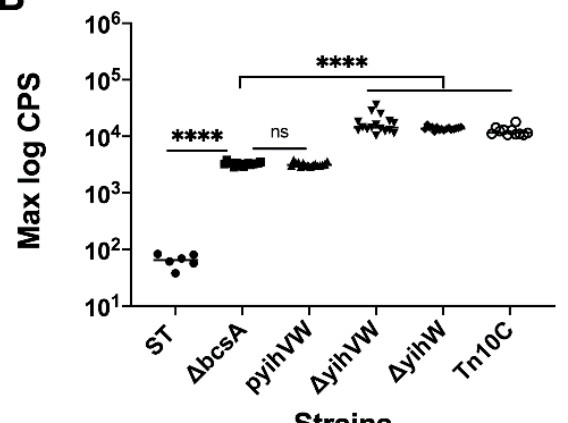

Figure 2. Expression of yihUTSRQPO and yihVW operons in $S$. Typhimurium. Promoter luciferase fusions for (A) yihUTSRQPO and (B) yihVW were used to measure expression in S. Typhimurium (ST, wildtype), S. Typhimurium $\triangle b c s A$ ( $\triangle \mathrm{bcsA}$ ), S. Typhimurium $\triangle b c s A$ pBR322-yihVW (pyihVW), S. Typhimurium $\triangle b c s A \triangle y i h V W(\Delta$ yihVW), S. Typhimurium $\triangle b c s A \Delta y i h W(\Delta y i h W)$ and $S$. Typhimurium $\triangle b c s A \Delta y i h W \operatorname{Tn} 10$ (Tn10C). Cultures were grown in $1 \%$ tryptone at $28^{\circ} \mathrm{C}$ with agitation, and luminescence (in counts per second (cps)) was recorded every $30 \mathrm{~min}$ for 48 hours. The log maximum CPS value recorded over 48 hours is shown. Statistical differences were noted as ${ }^{* * * *} p<0.0001$, ns: $p>0.05$. 
To determine if increased expression from the yihU operon would lead to increased production, O-Ag capsule was purified from $S$. Typhimurium $\triangle b c s A$ and $S$. Typhimurium $\triangle b c s A \Delta y i h W$ strains. Two times more crude CPS was purified from $S$. Typhimurium $\triangle b c s A$ $\triangle y i h W$ compared to $S$. Typhimurium $\triangle b c s A$. To isolate O-Ag capsule from crude CPS, anion and size exchange chromatography were performed and O-Ag capsule containing fractions were identified using EPS-specific serum. Similar quantities of O-Ag capsule were purified from $S$. Typhimurium $\Delta b c s A$ and $S$. Typhimurium $\Delta b c s A \Delta y i h W$ after chromatography (Table 3 ), suggesting that the increase in yihU expression did not lead to increased production of O-Ag capsule.

Table 3. Purification of CPS from S. Typhimurium wildtype and transposon mutants.

\begin{tabular}{|c|c|c|c|c|}
\hline $\begin{array}{c}\text { S. Typhimurium } \\
\text { Strains }^{\mathrm{A}}\end{array}$ & $\begin{array}{l}\text { Identified Site of } \\
\text { Tn10 Insertion }\end{array}$ & $\begin{array}{l}\text { Crude Polysaccharide } \\
\text { (mg) }\end{array}$ & $\begin{array}{l}\text { Polysaccharide after } \\
\text { Chromatography (mg) }\end{array}$ & $\begin{array}{c}\text { Endotoxin Removal } \\
\text { with Triton X-114 (mg) }\end{array}$ \\
\hline$\Delta b c s A$ & - & 59.5 & 12.5 & $<0.5$ \\
\hline$\Delta b c s A \Delta y i h W$ & & 130 & 18 & $<0.5$ \\
\hline Tn10A & Tnp IS200 & 132 & 41.1 & $<0.5$ \\
\hline $\operatorname{Tn} 10 \mathrm{~B}$ & fliD & 44 & - & - \\
\hline Tn10C & srfA & 500 & 157.2 & 10 \\
\hline Tn10D & stm14_2260 & 209 & 37 & $<2$ \\
\hline $\operatorname{Tn} 10 \mathrm{E}$ & fhlA & 332 & 49.8 & $<0.5$ \\
\hline $\operatorname{Tn} 10 \mathrm{~F}$ & ompS & 67 & - & - \\
\hline Tn10G & stm14_3662 & 344 & 61 & $<0.5$ \\
\hline $\operatorname{Tn} 10 \mathrm{C}(\mathrm{MOPS}){ }^{\mathrm{C}}$ & - & 2000 & 500 & 100 \\
\hline
\end{tabular}

A Tn10A-G are $\Delta b c s A \Delta y i h W$ mutant strains with Tn10Tet transposons inserted in the genome. ${ }^{\mathrm{B}}$ The amount of polysaccharide purified from 50 EPS agar plates is shown. ${ }^{C}$ Tn10C (MOPS) represents strain Tn10C grown in EPS agar buffered with 40 mM MOPS.

\subsection{Effect of Precursor Sugars on yihUTSRQPO Promoter Activity}

The lack of adequate amounts of precursor sugars could be one possible explanation for why 100-fold increased expression of the yihUTSRQPO operon in S. Typhimurium $\triangle b c s A \Delta y i h W$ did not lead to increased production of O-Ag capsule. Hence, we wanted to determine if increased amounts of $\mathrm{O}-\mathrm{Ag}$ capsule could be isolated from $\mathrm{S}$. Typhimurium $\triangle b c s A \Delta y i h W$ grown in media supplemented with precursor sugars required for O-Ag capsule biosynthesis. S. Typhimurium O-Ag capsule is made up of tetrasaccharide repeating units of galactose, rhamnose, mannose and abequose, with abequose and galactose residues partially substituted with a glucose side chain [17]. Using a luciferase reporter assay, we examined the effect of precursor sugars on yih $U$ expression. The addition of mannose, rhamnose and galactose to the growth media increased yihU expression approximately 5-fold in $S$. Typhimurium $\triangle b c s A$ (Figure 3A), while only the addition of mannose slightly increased yihU expression in S. Typhimurium $\triangle b c s A \triangle y i h W$ (Figure 3B). However, increased gene expression in the presence of precursor sugars had no measurable effect on O-Ag capsule production (data not shown). This indicated that the lack of increased $\mathrm{O}-\mathrm{Ag}$ capsule production by $S$. Typhimurium $\triangle b c s A \Delta y i h W$ was not due to the absence of an adequate amount of precursor sugars.

\subsection{Overproduction of CPS in Transposon Mutants}

Since increased expression of the yih operons and supplementation of growth media with precursor sugars did not boost the amount of O-Ag capsule purified from $\mathrm{S}$. Typhimurium $\triangle b c s A \Delta y i h W$, we hypothesized that other regulators besides yihW may be negatively regulating the biosynthesis of $\mathrm{O}-\mathrm{Ag}$ capsule. To identify unknown factors that negatively regulate CPS biosynthesis in Salmonella, random mutagenesis was performed in $S$. Typhimurium $\triangle b c s A \Delta y i h W$ using Tn10dtet transposon. It was expected that random mutagenesis in $S$. Typhimurium $\triangle b c s A \Delta y i h W$, with $\sim 100$-fold increased expression of yihU, would lead to a mutant strain that overproduces O-Ag capsule. 
A

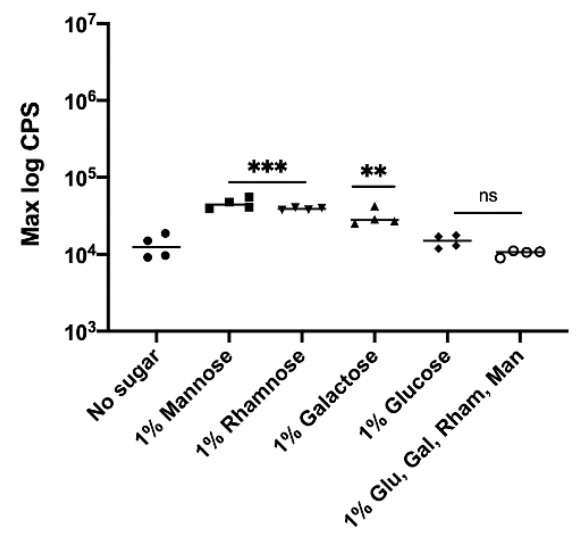

B

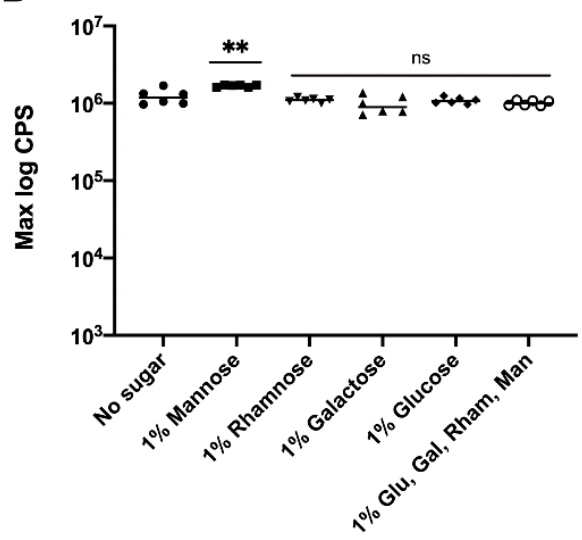

Figure 3. Effect of different precursor sugars on the expression of yihUTSRQPO. The S. Typhimurium $\triangle b c s A(\mathbf{A})$ and $S$. Typhimurium $\triangle b c s A \Delta y i h W(\mathbf{B})$ strains were grown in $1 \%$ tryptone media supplemented with or without different precursor sugars (glucose, galactose, rhamnose, mannose, or all four sugars), at $28^{\circ} \mathrm{C}$. Luminescence (in counts per second (cps)) was recorded every $30 \mathrm{~min}$ for 48 hours. The log maximum CPS value recorded over 48 hours is shown. Statistical differences were noted as ${ }^{* *} p<0.01,{ }^{* * *} p<0.001$, or ns: $p>0.05$.

Bacterial colonies overproducing CPS often have mucoid and watery surfaces that can be visually detected $[11,44]$, hence colony morphology was used to identify CPS overproducing strains. After random mutagenesis, seven potential high-CPS-producing isolates with mucoid morphologies were identified (named Tn10A-G). Nested PCR was used to identify the genomic sites of Tn10 insertions (Table 3), and crude CPS was purified from each mutant. At least 2 times more crude CPS was isolated from Tn10 C, D, E and G compared to $S$. Typhimurium $\Delta b c s A \Delta y i h W$ (Table 3). Following our standard O-Ag capsule purification procedure, $\sim 10$ times more material was obtained from mutant strain Tn10C, hence subsequent experiments were performed with this mutant. Using luciferase assays, we showed that yihU and yihVW expressions were similar in Tn10C and S. Typhimurium $\triangle b c s A \Delta y i h W$ (Figure 2), suggesting that increased yihU expression was not responsible for the increased amount of CPS produced in the Tn10C strain.

\subsection{Increased CPS Production by Salmonella Grown in Buffered Media}

$\mathrm{O}-\mathrm{Ag}$ capsule was purified from $S$. Typhimurium grown in EPS media with a carbon to nitrogen ratio of 10:1. We reasoned that a drop in $\mathrm{pH}$ due to increased glucose metabolism may reduce growth and limit the amount of CPS produced by $S$. Typhimurium $\triangle b c s A$ $\triangle y i h W$ Tn10C. Therefore, we investigated the effect of buffering the $\mathrm{pH}$ on CPS production. Approximately four times more crude CPS was isolated from strain Tn10C grown in EPS media buffered with MOPS compared to unbuffered media (Table 3).

\subsection{Overproduction of Colanic Acid in S. Typhimurium}

Since immune serum raised to whole Salmonella EPS [9] was used to guide the purification process, we performed monosaccharide composition analysis to characterize the final purified CPS. The amounts of fucose, galactose and glucose present in our crude and final purified CPS showed that colanic acid was purified from $S$. Typhimurium $\triangle b c s A \Delta y i h W$ Tn10C, and not O-Ag capsule (Table 4). Furthermore, detection of rhamnose and mannose suggests the presence of contaminating LPS in purified colanic acid.

WcaJ is a glycosylase that is part of the wca gene cluster important for the biosynthesis and transport of colanic acid in Salmonella [45]. To verify the overproduction of colanic acid, we generated a $S$. Typhimurium $\triangle b c s A \Delta y i h W$ Tn10C $\Delta w c a J$ strain. Deletion of wcaJ resulted in the loss of the mucoid morphology associated with CPS overproduction 
(data not shown), further indicating that colanic acid was being over-produced from $S$. Typhimurium $\triangle b c s A \Delta y i h W$ Tn10C.

Table 4. Monosaccharide composition (Mol\%) of crude and final purified CPS from Salmonella.

\begin{tabular}{ccccc}
\hline Monosaccharides & Crude CPS & $\begin{array}{c}\text { Polysaccharide Isolated } \\
\text { from Crude CPS }\end{array}$ & $\begin{array}{c}\text { Colanic } \\
\text { Acid }\end{array}$ & $\begin{array}{c}\text { O-Ag } \\
\text { Capsule }\end{array}$ \\
\hline Rhamnose & $3.6 \pm 0.3$ & $1.5 \pm 0.1$ & NA & 22 \\
Fucose & $32.3 \pm 0.9$ & $31.9 \pm 0.3$ & 27 & NA \\
Mannose & $5.7 \pm 0.2$ & $8.4 \pm 0.1$ & NA & 24 \\
Galactose & $35.2 \pm 0.4$ & $34.6 \pm 0.4$ & 28.8 & 28 \\
Abequose & $\mathrm{NT}$ & $\mathrm{NT}$ & $\mathrm{NA}$ & 18 \\
Glucose & $22.4 \pm 0.5$ & $22.4 \pm 0.3$ & 17.9 & 9.1 \\
\hline
\end{tabular}

Note: Experiments were conducted in triplicate. Sum of numbers presented in a column may not precisely be 100.0 due to rounding. NA: not applicable, NT: not tested. Reference for O-Ag capsule composition: Snyder et al. [17], colanic acid composition: Sutherland [8]

\subsection{Removal of Contaminating LPS from Purified CPS}

LPS is a common contaminant of purified CPS from Gram-negative bacteria, and since it is toxic in high amounts, the presence of LPS is not desirable in vaccine formulations [46]. Triton X-114 or acid hydrolysis with acetic acid are routinely used to remove LPS from purified CPS [38,39]. To determine the most efficient method for LPS elimination, purified colanic acid was treated with either Triton X-114 or acetic acid.

Triton X-114 is a non-ionic detergent that separates into detergent-rich and detergentpoor phases at room temperature [46]. When mixed with purified CPS, LPS preferentially goes into the detergent-rich phase, due to non-polar interactions between lipid A and Triton X-114 detergent. Several rounds of separation with Triton X-114 are usually performed to reduce the amount of LPS present in purified CPS [38]. We performed three rounds of LPS removal with Triton X-114, however increasing amounts of material were lost with each separation round. Only $50 \mathrm{mg}$ of colanic acid was isolated from $1000 \mathrm{mg}$ of crude CPS.

Following acid hydrolysis with acetic acid, the endotoxic portion of LPS, lipid A, is cleaved off the core oligosaccharide and forms precipitates which can be separated by centrifugation. After lipid A removal, colanic acid was purified using anion exchange and size exclusion chromatography. Approximately $200 \mathrm{mg}$ of colanic acid was purified from $1000 \mathrm{mg}$ of crude CPS.

After treatment with Triton X-114 or acid hydrolysis, the limulus amebocyte lysate (LAL) assay was used to quantify the amount of LPS (i.e., lipid A) present in purified colanic acid. About $4.9 \times 10^{4}$ endotoxin unit $(\mathrm{EU}) / \mathrm{mL}$ was present after three rounds of LPS removal with Triton X-114, while $1.4 \times 10^{4} \mathrm{EU} / \mathrm{mL}$ of LPS was present after treatment with acetic acid followed by size exclusion chromatography. LPS at a concentration between $1 \times 10^{3}$ and $4.55 \times 10^{6} \mathrm{EU} / \mathrm{mL}$ has been shown to be safe when administered to a $20 \mathrm{~g}$ mouse [46,47]. Hence, both methods reduced LPS to a safe level, however, less material was lost when acid hydrolysis was used for LPS elimination.

\subsection{Immune Response Induced by Colanic Acid}

The objective of this study was to boost the amount of CPS purified from $S$. Typhimurium for immunization trials. Random mutagenesis with Tn10dtet transposon aimed at increasing the amount of O-Ag capsule purified from $\mathrm{S}$. Typhimurium led to the overproduction of colanic acid. Colanic acid has previously been associated with survival in non-host environments [11,12], however since it is a conserved CPS, we wanted to determine if immunization with colanic acid could induce a protective immune response against Salmonella.

Groups of six BALB/c or C57BL/6 mice were immunized intramuscularly with $50 \mu \mathrm{g}$ of purified colanic acid formulated with TriAdj. TriAdj is a novel combination adjuvant platform comprised of (1) a TLR agonist, polyinosinic:polycytidylic acid (PolyI:C), (2) an immunostimulatory host defense peptide (HDP) and (3) polyphosphazene [48]. 
After primary immunization, two booster immunizations were administered at 21-day intervals. Immunization with colanic acid induced an anti-CPS acid IgG response in C57BL/ 6 (Figure 4A) and BALB/C (Figure 4B) mice.

A

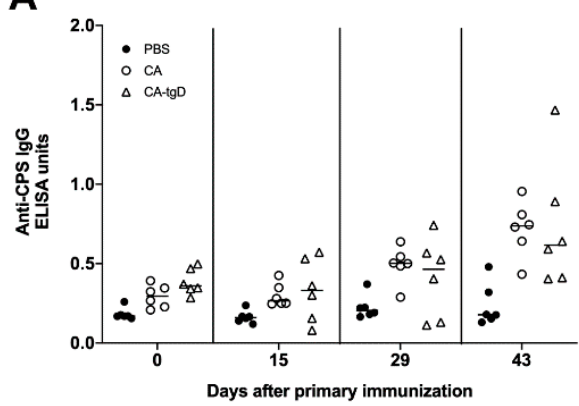

C

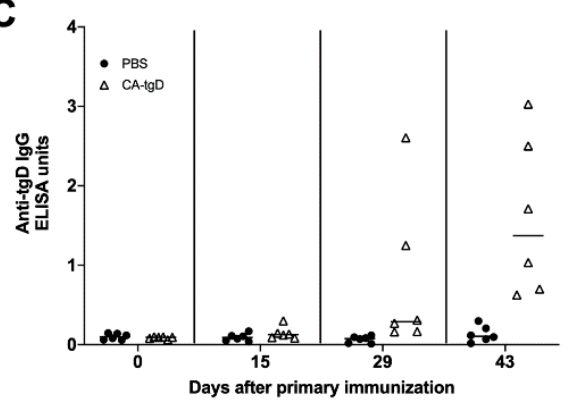

B
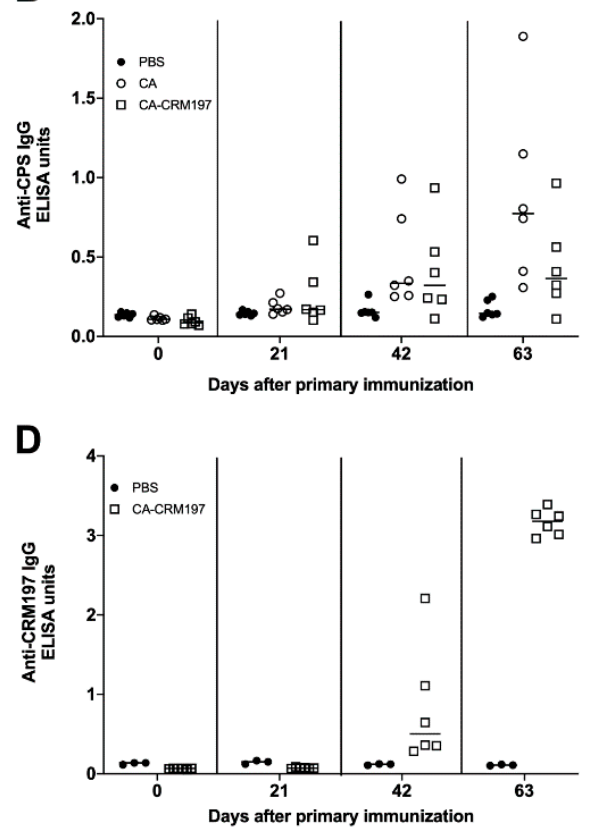

Figure 4. Immune response to colanic acid, truncated glycoprotein $\mathrm{D}$ and inactivated diphtheria toxin. ELISA was performed with serum collected from CB7BL/6 mice (A,C) or BALB/c mice (B,D), immunized with phosphate-buffered saline (PBS), colanic acid (CA), CA conjugated to inactivated diphtheria toxin (CA-CRM197) or CA conjugated to truncated glycoprotein D (CA-tgD).

To generate a specific and strong T-cell-dependent response, CPS are often conjugated to carrier proteins $[49,50]$. Colanic acid was conjugated to truncated bovine herpesvirus 1 glycoprotein $\mathrm{D}(\operatorname{tgD})$ [51,52] or the inactive form of diphtheria toxin (CRM197) [53]. In both cases, we detected high molecular weight material running above the size of the carrier proteins alone, indicating that successful conjugation had occurred (Supplementary Figure S1). C57BL $/ 6$ mice were immunized with $50 \mu \mathrm{g}$ of colanic acid conjugated to CRM197 (CA-CRM197), while BALB/c mice were immunized with $1 \mu \mathrm{g}$ of colanic acid conjugated to $\operatorname{tg} \mathrm{D}(\mathrm{CA}-\operatorname{tgD})$. Immunization with colanic acid or CA-CRM197 induced similar levels of anti-CPS IgG in C57BL/ 6 mice (Figure 4A). Immunization with colanic acid or CA-tgD also induced similar levels of anti-CA IgG in BALB/c mice (Figure 4B), however, mice were immunized with 50 times less CA-tgD.

Immunization with CA-CRM197 or CA-tgD induced robust anti-CRM197 IgG and anti-tgD IgG levels, respectively (Figure 4C,D). These results indicate that immunization with colanic acid alone or colanic acid conjugated to a carrier protein induced an immune response in mice.

\subsection{Immunization with Colanic Acid Does Not Induce a Protective Immune Response}

To determine if immunization with colanic acid or colanic acid conjugated to a carrier protein induced a protective immune response, mice were orally challenged with $10^{7} \mathrm{CFU}$ of $S$. Typhimurium three weeks after the final immunizations. Four to seven days postchallenge, mice were euthanized, and liver, spleen, cecum, MLN or blood were collected for bacterial enumeration. Approximately 1-log less Salmonella was recovered from C57BL/6 mice immunized with CA-CRM197 compared to mice immunized with PBS or colanic acid (Figure 5A). No significant difference in Salmonella CFU levels was detected from BALB/c mice immunized with colanic acid, CA-tgD or PBS (control) (Figure 5B). These results 
indicated that an immune response induced by colanic acid alone or conjugated to tgD was not protective against future Salmonella infections.

A

C57BL/6

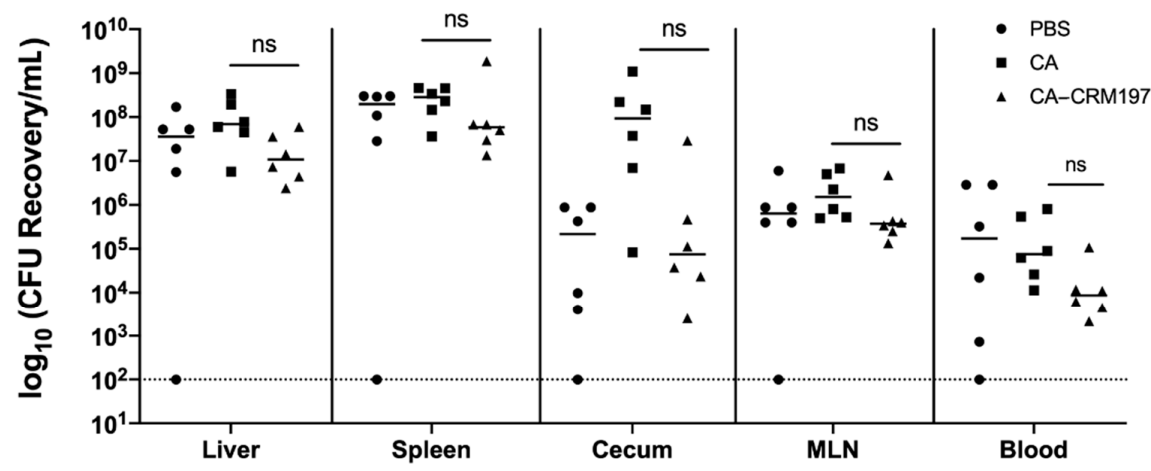

B

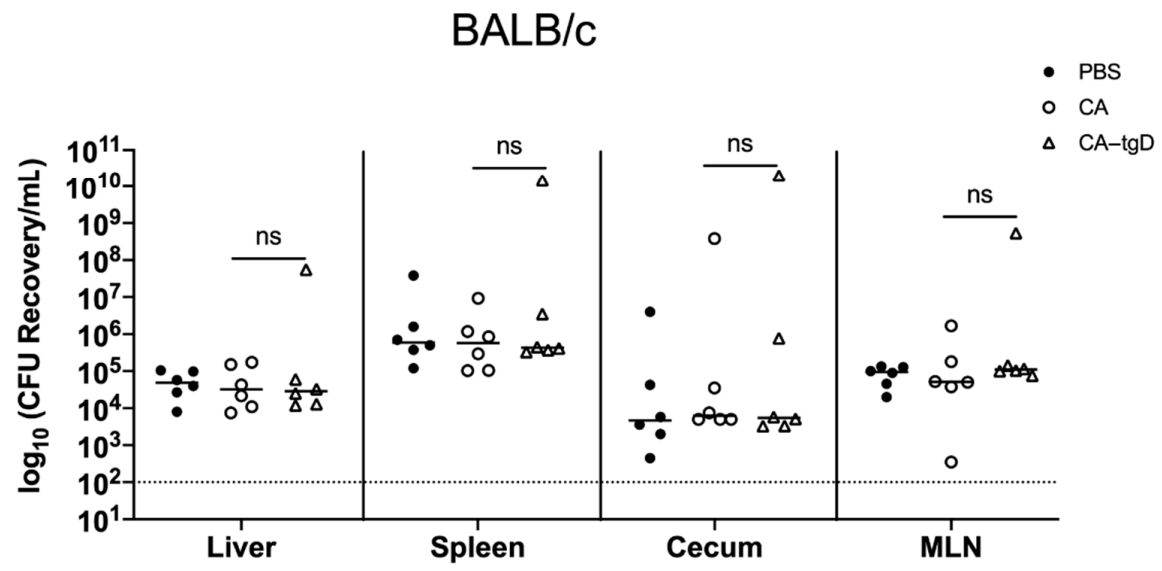

Figure 5. Amounts of $S$. Typhimurium recovered from mice previously immunized with colanic acid. (A) C57BL/ 6 mice were immunized with phosphate buffered saline (PBS), colanic acid (CA) or CA conjugated to inactivated diphtheria toxin (CA-CRM197). (B) BALB/c mice were immunized with PBS, CA or CA conjugated to truncated glycoprotein D (CA-tgD). All immunized mice were orally challenged with $10^{7} \mathrm{CFU}$ of Salmonella, and 4-7 days post-infection, the liver, spleen, cecum, mesenteric lymph node (MLN) and blood (C57BL/6) were harvested. Organs were homogenized before plating on LB agar supplemented with kanamycin. The $\log _{10}$ CFU values of Salmonella recovered from individual organs from each mouse are shown. The dashed line represents the limit of detection of $100 \mathrm{CFU}$. For each group of mice, the black line represents the median values. Statistical significance: Not significant (ns): $p>0.05$.

\subsection{Immunogenicity of GMMAs}

GMMAs are targets for vaccine development because they are rich sources of outer membrane antigens that can often induce a strong immune response [20]. We wanted to determine if immunization with GMMAs purified from CPS overproducing isolates would induce a protective immune response against Salmonella. The deletion of tolR affects the stability of the linkage between the inner and outer membrane and results in increased GMMA production [54,55]. A tolR mutation has previously been linked to increased GMMA production in Salmonella [22], hence we purified GMMAs from colanic acid overproducing Tn10C with a tolR deletion (Tn10C GMMAs). As controls, we also purified GMMAs from $S$. Typhimurium $\Delta$ tolR (wildtype GMMAs) and $S$. Typhimurium $\Delta$ tolR $\Delta$ lon (Lon GMMAs). Lon is a cytoplasmic serine protease responsible for the proteolytic 
cleavage of several proteins, and S. enterica strains with lon mutations have been shown to overproduce colanic acid [56].

Groups of six C57BL/ 6 mice were immunized intramuscularly with $50 \mu \mathrm{g}$ of GMMAs purified from each strain. Two booster immunizations of $5 \mu \mathrm{g}$ were given to each mouse at 3-week intervals. Serum from immunized mice was screened for the presence of antibodies that were specific to GMMAs and CPS. Immunization with GMMAs purified from wildtype, $\Delta$ lon or Tn10C strains induced a significant amount of anti-CPS antibodies 42 days after primary immunization (Figure 6A). There were no statistically significant differences between the amount of anti-CPS IgG induced by wildtype, Lon and Tn10C GMMAs.
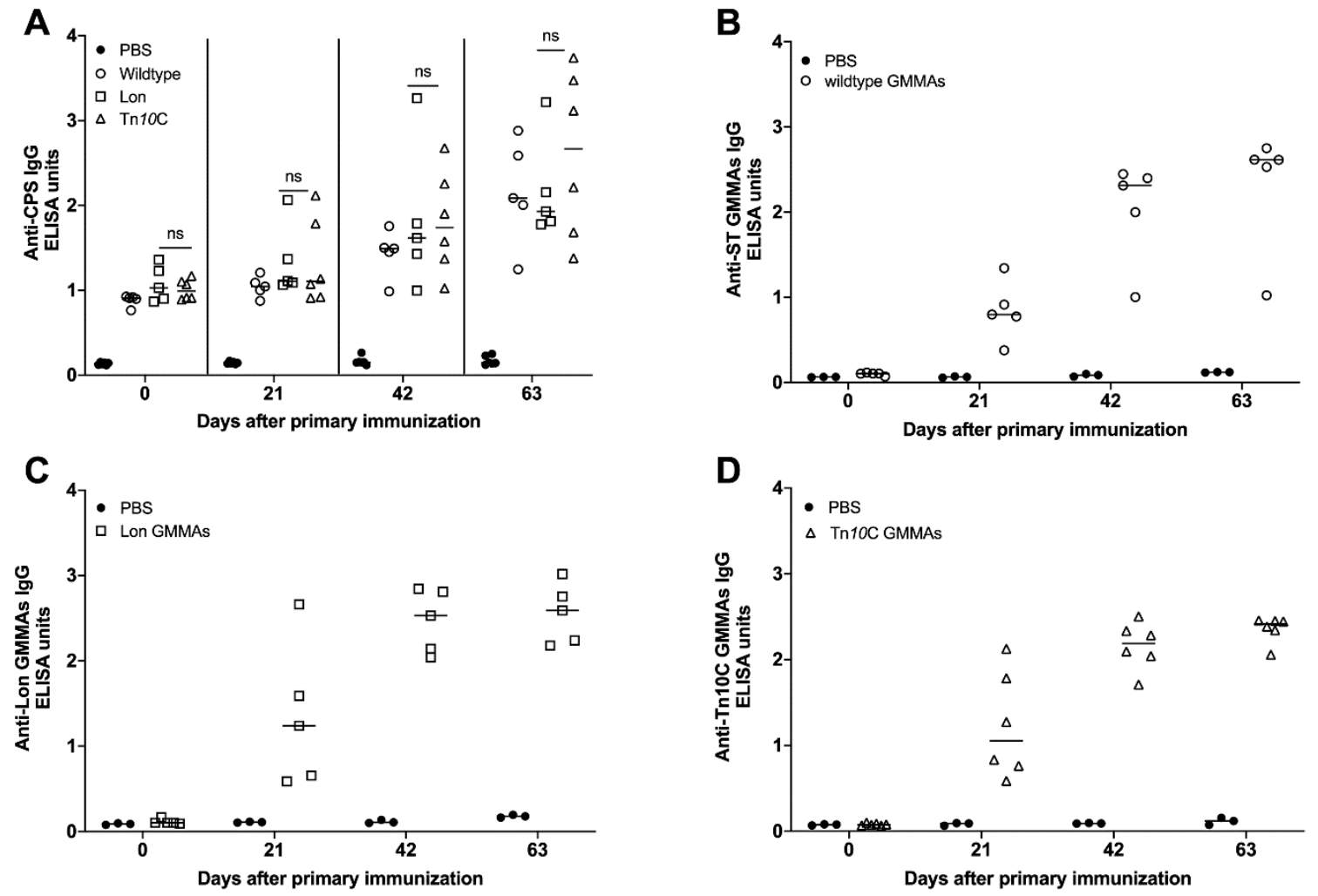

Figure 6. Immune response to GMMAs and colanic acid in immunized mice. Mice were immunized with GMMAs purified from S. Typhimurium $14028 \Delta$ tolR (wildtype), S. Typhimurium $14028 \Delta$ tolR $\Delta l o n$ (Lon), Tn10C $\Delta$ tolR (Tn10C) or PBS. ELISA was performed with sera collected on days 0, 21, 42 and 63 and used to detect Anti-CPS IgG (A), Anti- ST GMMAs IgG (wildtype) (B), Anti-Lon GMMAs IgG (C) and Anti-Tn10C GMMAs IgG (D). Each point represents the value from an individual mouse, the horizontal line represents the median from each group of mice. Statistical significance: ns: $p>0.05$.

Immunization with wildtype, Lon or Tn10C GMMAs induced increasing amounts of anti-GMMAs IgG on days 21, 42 and 63 (Figure 6B-D). Our results indicate that immunization with GMMAs induces CPS- and GMMA-specific immune responses.

\subsection{Immunization with GMMA Reduced Salmonella Colonization of Mice Organs}

To assess the level of protection induced by GMMAs, three weeks after the final immunizations, mice were orally challenged with $10^{7} \mathrm{CFU}$ of $S$. Typhimurium. All mice were euthanized 4-7 days after challenge and protection was assessed by the levels of $S$. Typhimurium colonization in the liver, spleen, cecum, MLN and in blood samples.

$S$. Typhimurium was not recovered from 3 of 5 mice immunized with wildtype GMMAs, and 4 of 5 mice immunized with Tn10C GMMAs, whereas 4 of 5 mice immunized with Lon GMMAs and 5 of 6 non-immunized control mice had significant levels of $S$. Typhimurium colonization (Figure 7). Based on these results, we hypothesize that im- 
munization with wildtype and Tn10C GMMAs induced a partially protective immune response against $S$. Typhimurium.

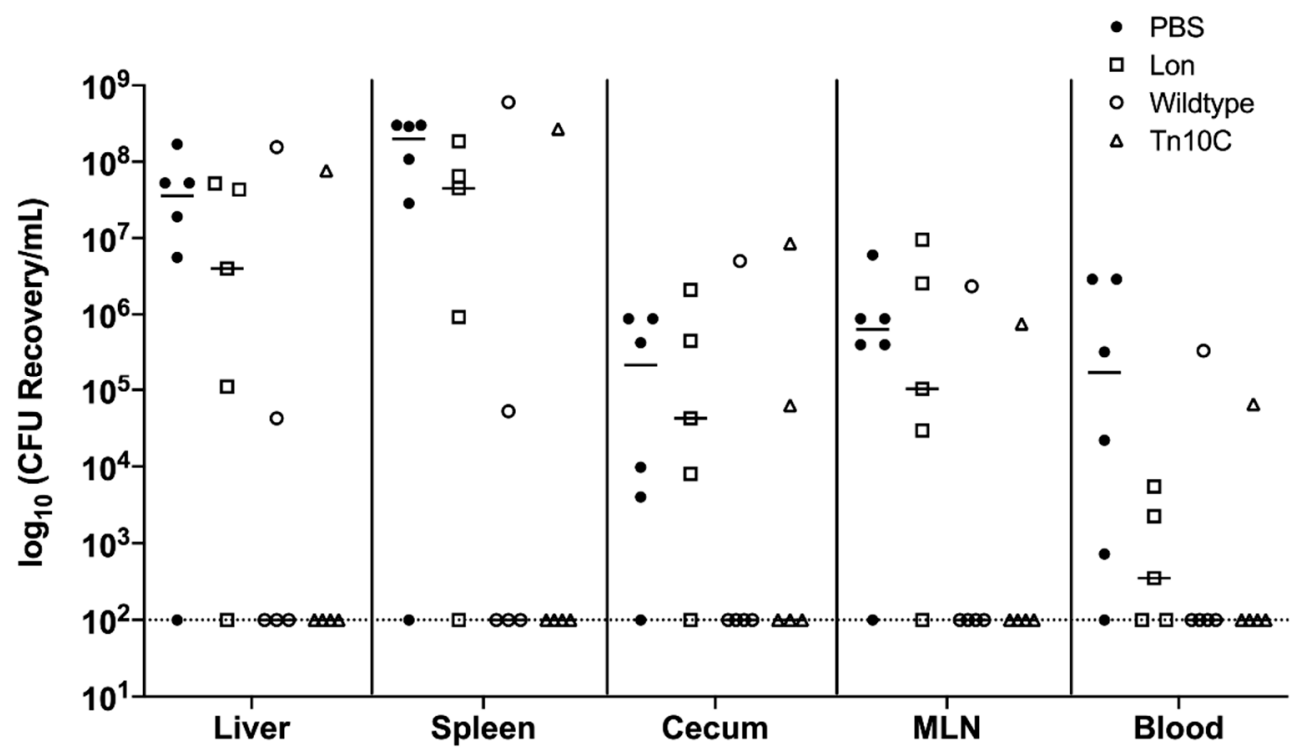

Figure 7. Ability of GMMAs to protect mice against lethal challenge of $S$. Typhimurium. C57BL/6 mice were immunized with PBS and GMMAs purified from $S$. Typhimurium $\Delta t o l R$ (wildtype), $S$. Typhimurium $\Delta$ tolR $\Delta l o n$ (Lon) and $S$. Typhimurium $\Delta$ tolR $\triangle b c s A \Delta y i h W$ Tn10dtet (Tn10C). Immunized mice were orally challenged with $10^{7} \mathrm{CFU}$ of $S$. Typhimurium 14028, and 4-7 days post-infection, mice were euthanized, and liver, spleen, cecum, MLN and blood were collected for bacterial enumeration. The $\log _{10}$ CFU of Salmonella recovered from each mouse is shown. The dotted line represents the limit of detection of 100 CFU. The black line represents the median log CFU values determined from each group of mice.

Mice immunized with wildtype or Tn10C GMMAs showed $\sim 5-\log$ reduction of bacterial colonization in the liver and spleen, and $\sim 3-\log$ reduction in the cecum, MLN and blood, compared to control mice (Figure 7). Mice immunized with Lon GMMAs showed a 1-log reduction in the liver, spleen, cecum and MLN and a 4-log reduction in the blood compared to control mice (Figure 7). Our results indicate that immunization with GMMAs reduces bacterial colonization of mice organs.

\section{Discussion}

Immune responses directed against CPS form the basis for some of the most successful human vaccines. CPS conjugated to carrier proteins are the basis for most CPS-based vaccines currently licensed for use, against human pathogens such as Haemophilius influenzae type b, Neisseria meningitidis, Streptococcus pneumoniae and Salmonella serovar Typhi [57-59]. There is currently no licensed vaccine against NTS. Due to the success of Vi CPS-based vaccines against typhoid fever [60,61], there is renewed interest in developing a CPS-based vaccine against NTS serovars that cause gastroenteritis and invasive blood stream infections.

Colanic acid is a common CPS mainly associated with survival of Salmonella cells in adverse environmental conditions [12]. However, it has been shown to contribute to Salmonella biofilm formation on mammalian cell lines and chicken intestinal epithelium [61]. The role of SrfA in CPS biosynthesis is unknown; however, insertional inactivation of srfA led to increased colanic acid production. SrfA is a virulence effector involved in modulating the host inflammatory response by promoting the activation of NF- $\mathrm{KB}$ signaling $[62,63]$. Since colanic acid may be produced in vivo during infection, we wanted to determine if a colanic acid-specific immune response could provide protection against lethal $S$. Typhimurium challenge. Similar CFU of Salmonella were recovered from mice immunized with colanic acid or PBS (control). Salmonella overproducing colanic acid has previously 
been shown to be susceptible to the bactericidal activity of human serum and to phagocytemediated killing $[44,64]$. Based on these results, we conclude that immunization with colanic acid does not induce a protective immune response. Although similar CFU values of $S$. Typhimurium were recovered from the organs of CA-tgD- and PBS-immunized mice, the reduced CFU recovered from mice immunized with CA-CRM197 suggests that colanic acid conjugated to CRM197 can induce a partially protective immune response in mice.

GMMAs are attractive vaccine candidates because they are comprised of multiple antigens that can stimulate an immune response [65]. Several studies have focused on developing GMMAs purified from bacteria with different genetic modifications as vaccine candidates for NTS [29]. GMMAs purified from S. Typhimurium with truncated LPS or deficient in flagellin production have been shown to induce cross-reactive antibody responses and cross-protection against Salmonella serovar Choleraesuis and Enteritidis [66,67]. Our results showed that GMMAs purified from colanic overproducing Salmonella reduced bacteria colonization in mice organs. Although Tn10C and Lon GMMAs were isolated from colanic acid overproducing strains, immunization with Tn10C GMMAs reduced bacterial colonization to a greater extent compared to Lon GMMAs. This result suggested the presence of different antigens on Tn10C GMMAs as compared to Lon-GMMAs. This conclusion is supported by several studies that have shown that the composition of GMMAs can vary with regards to growth phase, growth condition and genetic mutation present in bacteria [68-70]. Based on our results, we propose that engineered GMMAs with high CPS content should be developed as vaccine candidates. LPS-OAg and GMMAs alone have been shown to induce protective immune responses against NTS in mouse models of infection $[14,29]$. However, none of these antigens have been successfully developed as a vaccine against NTS. Since GMMAs indue a more diverse immune response [70], and LPSOAg is the target of protective immune response against NTS [14-16], we speculate that GMMAs with high concentrations of LPS-OAg will induce a diverse and cross-protective immune response against NTS.

The $S$. enterica O-Ag capsule was thought to be a potential vaccine candidate because it has similar repeating units as LPS O-Ag, which is the target of protective immunity against NTS [14-16]. Gibson et al. [9] speculated that precursor sugars synthesized by the LPS O-Ag machinery are modified, assembled and translocated out of the cell as O-Ag capsules by gene products from the divergent yihUTSRQPO and yihVW operons [9]. The increased expression of yihUTSRQPO in a $\triangle y i h W$ mutant is consistent with YihW being a repressor of the yih operons. The repressive effect of YihW has also been described in E. coli, where three yihW binding sites were identified in the yih promoter region [71,72]. Overexpression of genes often leads to the overproduction of specific proteins or CPS. However, a 100-fold increased expression of the yihUTSRQPO operon in the $\triangle y i h W$ mutant did not result in increased production of O-Ag capsule. The introduction of precursor sugars into growth media often leads to increased CPS biosynthesis [73-75]. However, $\mathrm{O}-\mathrm{Ag}$ capsule biosynthesis was not increased in the presence of excess precursor sugars. In addition, random mutagenesis aimed at increasing the amount of $\mathrm{O}-\mathrm{Ag}$ capsule produced by $S$. Typhimurium $\triangle b c s A \Delta y i h W$ led to increased colanic acid production. Based on these results, we speculate that the yih operons are not involved in biosynthesis of the O-Ag capsule.

Using enzymatic assays with purified proteins and mass spectrometric analysis of products, genes in the yih operons have been shown to be required for the catabolism of sulphoquinovose (SQ) by E. coli [76,77]. SQ is a major constituent of the human diet and about 10 pentagrams are produced by photosynthetic organisms annually [78]. Analysis of Salmonella mutants indicated that genes in the yih operons are involved in the colonization and persistence of Salmonella on plant surfaces [79,80], biofilm formation [81], resistance to desiccation [9] and resistance to killing by human immune serum [13]. Due to the high nucleotide $(80 \%)$ and protein $(80-92 \%)$ sequence identity with the E. coli operon, we speculate that the yih operons are also involved in SQ catabolism by S. enterica. However, due to the phenotypes associated with mutant strains, there is a possibility that genes in 
the yih operons have dual functionality. In Salmonella, the yih operons may be involved in SQ catabolism and in the synthesis of an unknown CPS or the modification of the antigenic content of the outer membrane. The serum used by Gibson et al. [9] for the initial identification of the yih operons was generated against whole Salmonella EPS fraction and was found to be cross-reactive to an uncharacterized CPS [9]. This might explain the lack of CPS in S. Typhimurium $\triangle$ yihO observed by Marshall and Gunn [13] using confocal microscopy $[9,13]$. A role for the yih operons in the modification of the antigenic content of the outer membrane provides an explanation for the exclusive production of phase 1 flagellin FliC by $S$. Typhimurium $\Delta y$ ih mutants, and the production of $\sim 25 \%$ to $45 \%$ more short LPS (with 1 to 8 LPS O-Ag repeating units) by S. Typhimurium $\Delta y$ ih mutants compared to wildtype [13]. More research is required to clarify the role of the yih operons in Salmonella.

Based on our research, we predict that the O-Ag capsule described by Gibson et al. [9] could represent very long-chain LPS O-Ag, which would provide an additional explanation for why increased expression of the yihU operon did not lead to increased O-Ag capsule production. S. Typhimurium has a tri-modal distribution of LPS due to the varying length of the O-Ag repeating units. Short LPS O-Ag (S-O-Ag) comprised of 1 to 15 repeating units, long LPS O-Ag (L-O-Ag) composed of 16 to 35 repeating units and very long LPS O-Ag (VL-O-Ag) comprised of more than 100 repeating units [82-84]. We speculate that the O-Ag capsule and VL-O-Ag could be the same CPS because they both have similar banding patterns on SDS-PAGE [9,13], are composed of similar tetrasaccharide repeat units [17] and have been implicated in similar functions $[13,83]$. Although the O-Ag capsule was found to be glycosylated at the tyvelose and galactose residues, high molecular weight LPS with varying glycosylation levels has been previously described in Salmonella [84]. Hence, the $\mathrm{O}-\mathrm{Ag}$ capsule may be VL-O-Ag glycosylated at the tyvelose and galactose sugars. More research is needed to determine the structure of this polysaccharide and others that are present on the cell surface of S. enterica isolates.

\section{Conclusions}

Although CPS has been the focus of subunit vaccine development against NTS, none have been tested in clinical trials. The immune response to LPS-O-Ag is strain-specific, while colanic acid does not induce a protective immune response. Research on CPS-based vaccines against NTS will have to focus on identifying novel CPS that can be developed as vaccines. Currently, GMMAs may be the best strategy for vaccine development, because they are highly immunogenic, deliver multiple antigens in their natural context and can induce a cross-protective immune response. With the rise in multi-drug-resistant isolates and the increasing incidence of invasive bloodstream infections, a vaccine is urgently needed to reduce the prevalence of NTS infections.

Supplementary Materials: The following are available online at https://www.mdpi.com/2076-3 93X/9/2/165/s1, Figure S1: Conjugation of S. Typhimurium CPS to carrier proteins. A,B. Western blots of truncated glycoprotein (tGD) conjugated to CPS, using tGD-specific immune serum (A) or CPS-specific immune serum (B) as the primary antibody. The same samples were loaded: tGD conjugated to itself (Lane 2), tGD alone (Lane 3) or tGD conjugated to CPS (Lane 4). Pre-stained protein ladder was loaded in Lane 1; the molecular weight of tGD was $66 \mathrm{kDa}$. C. SDS-PAGE analysis showing inactivated diphtheria toxin (CRM197) conjugated to CPS (Lanes 1 and 2), pre-stained protein ladder (Lane 3), and CRM197 alone (Lane 4). The molecular weight of CRM197 was $58 \mathrm{kDa}$.

Author Contributions: Conceptualization, A.P.W. and A.S.S.; methodology, A.P.W., A.S.S., S.A.-P. and S.T.; formal analysis, A.P.W., A.S.S. and S.R.P.; investigation, A.S.S., S.R.P., Z.S., R.K., L.R.B., X.X., S.L., W.D., D.W.A. and S.T.; resources, A.P.W.; data curation, A.P.W. and A.S.S.; writing-original draft preparation, A.S.S.; writing-review and editing, A.P.W. and A.S.S.; supervision, A.P.W.; project administration, A.P.W.; funding acquisition, A.P.W. All authors have read and agreed to the published version of the manuscript. 
Funding: This research was supported by a Natural Sciences and Engineering Research Council (NSERC) Discovery grant (Grant \#2017-05737 to A.P.W.), the Jarislowsky Chair in Biotechnology (A.P.W.), and the University of Saskatchewan (Graduate research fellowship to A.S.S.; Biomedical research awards to Z.S., R.K. and L.R.B.). The funders had no role in study design, data collection and analysis, decision to publish, or preparation of the manuscript.

Institutional Review Board Statement: All animals were cared for and used in accordance with the Guidelines of the Canadian Council on Animal Care and the Regulations of the University of Saskatchewan Committee on Animal Care and Supply. All animal experiments were performed under Animal Use Protocols \#20170066 and \#20190071, which were approved by the University of Saskatchewan's Animal Research Ethics Board.

Informed Consent Statement: Not applicable.

Data Availability Statement: The data presented in this study are available on request from the corresponding author.

Acknowledgments: We are grateful to Colette Wheler, Sherri Tetland, Jan Erickson, and the VIDO animal care staff for professional help with the animal experiments. We are also grateful to Melissa Palmer and Fangning Liu for their help with animal trials. Published as VIDO manuscript series no. 920 .

Conflicts of Interest: The authors declare no conflict of interest.

\section{References}

1. Kirk, M.D.; Pires, S.M.; Black, R.E.; Caipo, M.; Crump, J.A.; Devleesschauwer, B.; Döpfer, D.; Fazil, A.; Fischer-Walker, C.L.; Hald, T.; et al. World Health Organization Estimates of the Global and Regional Disease Burden of 22 Foodborne Bacterial, Protozoal, and Viral Diseases, 2010: A Data Synthesis. PLoS Med. 2015, 12, e1001921. [CrossRef]

2. Gal-Mor, O.; Boyle, E.C.; Grassl, G.A. Same Species, Different Diseases: How and Why Typhoidal and Non-Typhoidal Salmonella Enterica Serovars Differ. Front. Microbiol. 2014, 5, 391. [CrossRef]

3. Majowicz, S.E.; Musto, J.; Scallan, E.; Angulo, F.J.; Kirk, M.; O’Brien, S.J.; Jones, T.F.; Fazil, A.; Hoekstra, R.M.; for the International Collaboration on Enteric Disease "Burden of Illness" Studies. The Global Burden of Nontyphoidal Salmonella Gastroenteritis. Clin. Infect. Dis. 2010, 50, 882-889. [CrossRef] [PubMed]

4. $\quad$ Eng, S.-K.; Pusparajah, P.; Mutalib, N.-S.A.; Ser, H.-L.; Chan, K.-G.; Lee, L.-H. Salmonella: A Review on Pathogenesis, Epidemiology and Antibiotic Resistance. Front. Life Sci. 2015, 8, 284-293. [CrossRef]

5. Reddy, E.A.; Shaw, A.V.; Crump, J.A. Community-Acquired Bloodstream Infections in Africa: A Systematic Review and Meta-Analysis. Lancet Infect. Dis. 2010, 10, 417-432. [CrossRef]

6. Feasey, N.A.; Dougan, G.; Kingsley, R.A.; Heyderman, R.S.; Gordon, M.A. Invasive Non-Typhoidal Salmonella Disease: An Emerging and Neglected Tropical Disease in Africa. Lancet Lond. Engl. 2012, 379, 2489-2499. [CrossRef]

7. Flemming, H.-C. EPS-Then and Now. Microorganisms 2016, 4, 41. [CrossRef] [PubMed]

8. Sutherland, I.W. Structural Studies on Colanic Acid, the Common Exopolysaccharide Found in the Enterobacteriaceae, by Partial Acid Hydrolysis. Oligosaccharides from Colanic Acid. Biochem. J. 1969, 115, 935-945. [CrossRef]

9. Gibson, D.L.; White, A.P.; Snyder, S.D.; Martin, S.; Heiss, C.; Azadi, P.; Surette, M.; Kay, W.W. Salmonella Produces an O-Antigen Capsule Regulated by AgfD and Important for Environmental Persistence. J. Bacteriol. 2006, 188, 7722-7730. [CrossRef]

10. Raetz, C.R.H.; Whitfield, C. Lipopolysaccharide Endotoxins. Annu. Rev. Biochem. 2002, 71, 635-700. [CrossRef]

11. Goebel, W.F. COLANIC ACID. Proc. Natl. Acad. Sci. USA 1963, 49, 464-471. [CrossRef]

12. Steenackers, H.; Hermans, K.; Vanderleyden, J.; Keersmaecker, S.C.J.D. Salmonella Biofilms: An Overview on Occurrence, Structure, Regulation and Eradication. Food Res. Int. 2012, 45, 502-531. [CrossRef]

13. Marshall, J.M.; Gunn, J.S. The O-Antigen Capsule of Salmonella Enterica Serovar Typhimurium Facilitates Serum Resistance and Surface Expression of FliC. Infect. Immun. 2015, 83, 3946-3959. [CrossRef] [PubMed]

14. Rondini, S.; Lanzilao, L.; Necchi, F.; O’Shaughnessy, C.M.; Micoli, F.; Saul, A.; MacLennan, C.A. Invasive African Salmonella Typhimurium Induces Bactericidal Antibodies against O-Antigens. Microb. Pathog. 2013, 63, 19-23. [CrossRef] [PubMed]

15. Goh, Y.S.; Clare, S.; Micoli, F.; Saul, A.; Mastroeni, P.; MacLennan, C.A. Monoclonal Antibodies of a Diverse Isotype Induced by an O-Antigen Glycoconjugate Vaccine Mediate In Vitro and In Vivo Killing of African Invasive Nontyphoidal Salmonella. Infect. Immun. 2015, 83, 3722-3731. [CrossRef] [PubMed]

16. Rondini, S.; Micoli, F.; Lanzilao, L.; Gavini, M.; Alfini, R.; Brandt, C.; Clare, S.; Mastroeni, P.; Saul, A.; MacLennan, C.A. Design of Glycoconjugate Vaccines against Invasive African Salmonella Enterica Serovar Typhimurium. Infect. Immun. 2015, 83, 996-1007. [CrossRef]

17. Snyder, D.S.; Gibson, D.; Heiss, C.; Kay, W.; Azadi, P. Structure of a Capsular Polysaccharide Isolated from Salmonella enteritidis. Carbohyd. Res. 2006, 341, 2388-2397. [CrossRef] 
18. Phalipon, A.; Tanguy, M.; Grandjean, C.; Guerreiro, C.; Bélot, F.; Cohen, D.; Sansonetti, P.J.; Mulard, L.A. A Synthetic CarbohydrateProtein Conjugate Vaccine Candidate against Shigella Flexneri 2a Infection. J. Immunol. Baltim. Md. 1950 2009, 182, $2241-2247$. [CrossRef]

19. Romero-Steiner, S.; Fernandez, J.; Biltoft, C.; Wohl, M.E.; Sanchez, J.; Feris, J.; Balter, S.; Levine, O.S.; Carlone, G.M. Functional Antibody Activity Elicited by Fractional Doses Of Haemophilus Influenzae Type b Conjugate Vaccine (Polyribosylribitol Phosphate-Tetanus Toxoid Conjugate). Clin. Diagn. Lab. Immun. 2001, 8, 1115-1119. [CrossRef]

20. Jan, A.T. Outer Membrane Vesicles (OMVs) of Gram-Negative Bacteria: A Perspective Update. Front. Microbiol. 2017, 8, 1053. [CrossRef]

21. Schwechheimer, C.; Kuehn, M.J. Outer-Membrane Vesicles from Gram-Negative Bacteria: Biogenesis and Functions. Nat. Rev. Microbiol. 2015, 13, 605-619. [CrossRef]

22. Bernadac, A.; Gavioli, M.; Lazzaroni, J.C.; Raina, S.; Lloubès, R. Escherichia Coli Tol-Pal Mutants Form Outer Membrane Vesicles. J. Bacteriol. 1998, 180, 4872-4878. [CrossRef]

23. Henry, T.; Pommier, S.; Journet, L.; Bernadac, A.; Gorvel, J.-P.; Lloubès, R. Improved Methods for Producing Outer Membrane Vesicles in Gram-Negative Bacteria. Res. Microbiol. 2004, 155, 437-446. [CrossRef] [PubMed]

24. Scorza, F.B.; Doro, F.; Rodríguez-Ortega, M.J.; Stella, M.; Liberatori, S.; Taddei, A.R.; Serino, L.; Moriel, D.G.; Nesta, B.; Fontana, M.R.; et al. Proteomics Characterization of Outer Membrane Vesicles from the Extraintestinal Pathogenic Escherichia coli $\Delta$ tolR IHE3034 Mutant. Mol. Cell Proteom. Mcp. 2007, 7, 473-485. [CrossRef]

25. Chen, D.J.; Osterrieder, N.; Metzger, S.M.; Buckles, E.; Doody, A.M.; DeLisa, M.P.; Putnam, D. Delivery of Foreign Antigens by Engineered Outer Membrane Vesicle Vaccines. Proc. Natl. Acad. Sci. USA 2010, 107, 3099-3104. [CrossRef] [PubMed]

26. Kim, J.-Y.; Doody, A.M.; Chen, D.J.; Cremona, G.H.; Shuler, M.L.; Putnam, D.; DeLisa, M.P. Engineered Bacterial Outer Membrane Vesicles with Enhanced Functionality. J. Mol. Biol. 2008, 380, 51-66. [CrossRef]

27. Ellis, T.N.; Kuehn, M.J. Virulence and Immunomodulatory Roles of Bacterial Outer Membrane Vesicles. Microbiol. Mol. Biol. R. 2010, 74, 81-94. [CrossRef] [PubMed]

28. Vipond, C.; Wheeler, J.X.; Jones, C.; Feavers, I.M.; Suker, J. Characterization of the Protein Content of a Meningococcal Outer Membrane Vesicle Vaccine by Polyacrylamide Gel Electrophoresis and Mass Spectrometry. Hum. Vaccines 2005, 1, 80-84. [CrossRef]

29. Micoli, F.; Rondini, S.; Alfini, R.; Lanzilao, L.; Necchi, F.; Negrea, A.; Rossi, O.; Brandt, C.; Clare, S.; Mastroeni, P.; et al. Comparative Immunogenicity and Efficacy of Equivalent Outer Membrane Vesicle and Glycoconjugate Vaccines against Nontyphoidal Salmonella. Proc. Natl. Acad. Sci. USA 2018, 115, 10428-10433. [CrossRef]

30. Elliott, T.; Roth, J.R. Characterization of Tn10d-Cam: A Transposition-Defective Tn10 Specifying Chloramphenicol Resistance. Mol. Gen. Genet. MGG 1988, 213, 332-338. [CrossRef]

31. White, A.P.; Gibson, D.L.; Kim, W.; Kay, W.W.; Surette, M.G. Thin Aggregative Fimbriae and Cellulose Enhance Long-Term Survival and Persistence of Salmonella. J. Bacteriol. 2006, 188, 3219-3227. [CrossRef]

32. Way, J.C.; Davis, M.A.; Morisato, D.; Roberts, D.E.; Kleckner, N. New Tn10 Derivatives for Transposon Mutagenesis and for Construction of LacZ Operon Fusions by Transposition. Gene 1984, 32, 369-379. [CrossRef]

33. Bjarnason, J.; Southward, C.M.; Surette, M.G. Genomic Profiling of Iron-Responsive Genes in Salmonella Enterica Serovar Typhimurium by High-Throughput Screening of a Random Promoter Library. J. Bacteriol. 2003, 185, 4973-4982. [CrossRef] [PubMed]

34. Datsenko, K.A.; Wanner, B.L. One-Step Inactivation of Chromosomal Genes in Escherichia coli K-12 Using PCR Products. Proc. National Acad. Sci. USA 2000, 97, 6640-6645. [CrossRef] [PubMed]

35. Maloy, S.R.; Stewart, V.J.; Taylor, R.K. Genetic Analysis of Pathogenic Bacteria: A Laboratory Manual; Cold Spring Harbor Laboratory Press: Plainview, NY, USA, 1996.

36. Wood, J.A.; Tan, H.; Collins, H.M.; Yap, K.; Khor, S.F.; Lim, W.L.; Xing, X.; Bulone, V.; Burton, R.A.; Fincher, G.B.; et al. Genetic and Environmental Factors Contribute to Variation in Cell Wall Composition in Mature Desi Chickpea (Cicer Arietinum L.) Cotyledons. Plant. Cell Environ. 2018, 41, 2195-2208. [CrossRef] [PubMed]

37. Pettolino, F.A.; Walsh, C.; Fincher, G.B.; Bacic, A. Determining the Polysaccharide Composition of Plant Cell Walls. Nat. Protoc. 2012, 7, 1590-1607. [CrossRef] [PubMed]

38. Adam, O.; Vercellone, A.; Paul, F.; Monsan, P.F.; Puzo, G. A Nondegradative Route for the Removal of Endotoxin from Exopolysaccharides. Anal. Biochem. 1995, 225, 321-327. [CrossRef] [PubMed]

39. Bordier, C. Phase Separation of Integral Membrane Proteins in Triton X-114 Solution. J. Biol. Chem. 1981, 256, 1604-1607. [CrossRef]

40. Qiao, W.; Ji, S.; Zhao, Y.; Hu, T. Conjugation of $\beta$-Glucan Markedly Increase the Immunogencity of Meningococcal Group Y Polysaccharide Conjugate Vaccine. Vaccine 2015, 33, 2066-2072. [CrossRef]

41. van Drunen Littel-van den Hurk, S.; Donkersgoed, J.V.; Kowalski, J.; van den Hurk, J.V.; Harland, R.; Babiuk, L.A.; Zamb, T.J. A Subunit GIV Vaccine, Produced by Transfected Mammalian Cells in Culture, Induces Mucosal Immunity against Bovine Herpesvirus-1 in Cattle. Vaccine 1994, 12, 1295-1302. [CrossRef]

42. Shivak, D.J.; MacKenzie, K.D.; Watson, N.L.; Pasternak, J.A.; Jones, B.D.; Wang, Y.; DeVinney, R.; Wilson, H.L.; Surette, M.G.; White, A.P. A Modular, Tn7-Based System for Making Bioluminescent or Fluorescent Salmonella and Escherichia Coli Strains. Appl. Environ. Microb. 2016, 82, 4931-4943. [CrossRef] 
43. White, A.P.; Gibson, D.L.; Grassl, G.A.; Kay, W.W.; Finlay, B.B.; Vallance, B.A.; Surette, M.G. Aggregation via the Red, Dry, and Rough Morphotype Is Not a Virulence Adaptation in Salmonella Enterica Serovar Typhimurium. Infect. Immun. 2008, 76, 1048-1058. [CrossRef] [PubMed]

44. Allen, P.M.; Fisher, D.; Saunders, J.R.; Hart, C.A. The Role of Capsular Polysaccharide K2 $1 \mathrm{~b}$ of Klebsiella and of the Structurally Related Colanic-Acid Polysaccharide of Escherichia coli in Resistance to Phagocytosis and Serum Killing. J. Med. Microbiol. 1987, 24, 363-370. [CrossRef]

45. Stevenson, G.; Lan, R.; Reeves, P.R. The Colanic Acid Gene Cluster of Salmonella Enterica Has a Complex History. FEMS Microbiol. Lett. 2000, 191, 11-16. [CrossRef]

46. Copeland, S.; Warren, H.S.; Lowry, S.F.; Calvano, S.E.; Remick, D.; the Inflammation and the Host Response to Injury Investigators. Acute Inflammatory Response to Endotoxin in Mice and Humans. Clin. Diagnostic. Lab. Immunol. 2005, 12, 60-67. [CrossRef]

47. Magalhães, P.O.; Lopes, A.M.; Mazzola, P.G.; Rangel-Yagui, C.; Penna, T.C.V.; Pessoa, A. Methods of Endotoxin Removal from Biological Preparations: A Review. J. Pharm. Pharm. Sci. Publ. Can. Soc. Pharm. Sci. Société. Can. Des. Sci. Pharm. 2007, 10, 388-404.

48. Beutler, B.; Milsark, I.; Cerami, A. Passive Immunization against Cachectin/Tumor Necrosis Factor Protects Mice from Lethal Effect of Endotoxin. Science 1985, 229, 869-871. [CrossRef]

49. Garg, R.; Babiuk, L.; van Drunen Littel-van den Hurk, S.; Gerdts, V. A Novel Combination Adjuvant Platform for Human and Animal Vaccines. Vaccine 2017, 35, 4486-4489. [CrossRef] [PubMed]

50. Lesinski, G.; Westerink, M.A.J. Vaccines Against Polysaccharide Antigens. Curr. Drug Target.-Infect. Disord. 2001, 1, 325-334. [CrossRef] [PubMed]

51. Rappuoli, R. Glycoconjugate Vaccines: Principles and Mechanisms. Sci. Transl. Med. 2018, 10, eaat4615. [CrossRef]

52. Dummer, L.A.; Leite, F.P.L.; van Drunen Littel-van den Hurk, S. Bovine Herpesvirus Glycoprotein D: A Review of Its Structural Characteristics and Applications in Vaccinology. Vet. Res. 2014, 45, 111. [CrossRef] [PubMed]

53. Manoj, S.; Babiuk, L.A.; van Drunen Littel-van den Hurk, S. Immunization with a Dicistronic Plasmid Expressing a Truncated Form of Bovine Herpesvirus-1 Glycoprotein D and the Amino-Terminal Subunit of Glycoprotein B Results in Reduced GB-Specific Immune Responses. Virology 2003, 313, 296-307. [CrossRef]

54. Malito, E.; Bursulaya, B.; Chen, C.; Surdo, P.L.; Picchianti, M.; Balducci, E.; Biancucci, M.; Brock, A.; Berti, F.; Bottomley, M.J.; et al. Structural Basis for Lack of Toxicity of the Diphtheria Toxin Mutant CRM197. Proc. Natl. Acad. Sci. USA 2012, 109, 5229-5234. [CrossRef]

55. Meloni, E.; Colucci, A.M.; Micoli, F.; Sollai, L.; Gavini, M.; Saul, A.; Cioccio, V.D.; MacLennan, C.A. Simplified Low-Cost Production of O-Antigen from Salmonella Typhimurium Generalized Modules for Membrane Antigens (GMMA). J. Biotechnol. 2015, 198, 46-52. [CrossRef]

56. Benedetto, G.D.; Alfini, R.; Cescutti, P.; Caboni, M.; Lanzilao, L.; Necchi, F.; Saul, A.; MacLennan, C.A.; Rondini, S.; Micoli, F. Characterization of O-Antigen Delivered by Generalized Modules for Membrane Antigens (GMMA) Vaccine Candidates against Nontyphoidal Salmonella. Vaccine 2017, 35, 419-426. [CrossRef] [PubMed]

57. Downs, D.; Waxman, L.; Goldberg, A.L.; Roth, J. Isolation and Characterization of Lon Mutants in Salmonella Typhimurium. J. Bacteriol. 1986, 165, 193-197. [CrossRef] [PubMed]

58. Jones, C. Vaccines Based on the Cell Surface Carbohydrates of Pathogenic Bacteria. Anais Acad. Bras. Ciências 2005, 77, 293-324. [CrossRef] [PubMed]

59. Finn, A. Bacterial Polysaccharide-Protein Conjugate Vaccines. Brit. Med. Bull. 2004, 70, 1-14. [CrossRef]

60. Mettu, R.; Chen, C.-Y.; Wu, C.-Y. Synthetic Carbohydrate-Based Vaccines: Challenges and Opportunities. J. Biomed. Sci. 2020, 27, 9. [CrossRef] [PubMed]

61. Guzman, C.A.; Borsutzky, S.; Griot-Wenk, M.; Metcalfe, I.C.; Pearman, J.; Collioud, A.; Favre, D.; Dietrich, G. Vaccines against Typhoid Fever. Vaccine 2006, 24, 3804-3811. [CrossRef]

62. Ledeboer, N.A.; Jones, B.D. Exopolysaccharide Sugars Contribute to Biofilm Formation by Salmonella Enterica Serovar Typhimurium on HEp-2 Cells and Chicken Intestinal Epithelium. J. Bacteriol. 2005, 187, 3214-3226. [CrossRef] [PubMed]

63. Lei, L.; Wang, W.; Xia, C.; Liu, F. Salmonella Virulence Factor SsrAB Regulated Factor Modulates Inflammatory Responses by Enhancing the Activation of NF-KB Signaling Pathway. J. Immunol. 2016, 196, 792-802. [CrossRef] [PubMed]

64. Worley, M.J.; Ching, K.H.L.; Heffron, F. Salmonella SsrB Activates a Global Regulon of Horizontally Acquired Genes. Mol. Microbiol. 2000, 36, 749-761. [CrossRef] [PubMed]

65. Ondari, E.M.; Klemm, E.J.; Msefula, C.L.; Ghany, M.A.E.; Heath, J.N.; Pickard, D.J.; Barquist, L.; Dougan, G.; Kingsley, R.A.; MacLennan, C.A. Rapid Transcriptional Responses to Serum Exposure Are Associated with Sensitivity and Resistance to Antibody-Mediated Complement Killing in Invasive Salmonella Typhimurium ST313. Wellcome Open Res. 2019, 4, 74. [CrossRef]

66. Alaniz, R.C.; Deatherage, B.L.; Lara, J.C.; Cookson, B.T. Membrane Vesicles Are Immunogenic Facsimiles of Salmonella Typhimurium That Potently Activate Dendritic Cells, Prime B and T Cell Responses, and Stimulate Protective Immunity In Vivo. J. Immunol. 2007, 179, 7692-7701. [CrossRef]

67. Liu, Q.; Liu, Q.; Yi, J.; Liang, K.; Liu, T.; Roland, K.L.; Jiang, Y.; Kong, Q. Outer Membrane Vesicles Derived from Salmonella Typhimurium Mutants with Truncated LPS Induce Cross-Protective Immune Responses against Infection of Salmonella enterica Serovars in the Mouse Model. Int. J. Med. Microbiol. Ijmm. 2016, 306, 697-706. [CrossRef] 
68. Liu, Q.; Liu, Q.; Yi, J.; Liang, K.; Hu, B.; Zhang, X.; Curtiss, R.; Kong, Q. Outer Membrane Vesicles from Flagellin-Deficient Salmonella enterica Serovar Typhimurium Induce Cross-Reactive Immunity and Provide Cross-Protection against Heterologous Salmonella Challenge. Sci. Rep. 2016, 6, 34776. [CrossRef]

69. Bai, J.; Kim, S.I.; Ryu, S.; Yoon, H. Identification and Characterization of Outer Membrane Vesicle-Associated Proteins in Salmonella enterica Serovar Typhimurium. Infect. Immun. 2014, 82, 4001-4010. [CrossRef]

70. Rossi, O.; Caboni, M.; Negrea, A.; Necchi, F.; Alfini, R.; Micoli, F.; Saul, A.; MacLennan, C.A.; Rondini, S.; Gerke, C. Toll-Like Receptor Activation by Generalized Modules for Membrane Antigens from Lipid A Mutants of Salmonella enterica Serovars Typhimurium and Enteritidis. Clin. Vaccin. Immunol. 2016, 23, 304-314. [CrossRef] [PubMed]

71. Malabirade, A.; Habier, J.; Heintz-Buschart, A.; May, P.; Godet, J.; Halder, R.; Etheridge, A.; Galas, D.; Wilmes, P.; Fritz, J.V. The RNA Complement of Outer Membrane Vesicles From Salmonella enterica Serovar Typhimurium Under Distinct Culture Conditions. Front. Microbiol. 2018, 9, 2015. [CrossRef]

72. Shimada, T.; Yamamoto, K.; Nakano, M.; Watanabe, H.; Schleheck, D.; Ishihama, A. Regulatory Role of CsqR (YihW) in Transcription of the Genes for Catabolism of the Anionic Sugar Sulfoquinovose (SQ) in Escherichia coli K-12. Microbiology+ 2019, 165, 78-89. [CrossRef] [PubMed]

73. Kaznadzey, A.; Shelyakin, P.; Belousova, E.; Eremina, A.; Shvyreva, U.; Bykova, D.; Emelianenko, V.; Korosteleva, A.; Tutukina, M.; Gelfand, M.S. The Genes of the Sulphoquinovose Catabolism in Escherichia coli Are Also Associated with a Previously Unknown Pathway of Lactose Degradation. Sci. Rep. 2018, 8, 3177. [CrossRef]

74. Looijesteijn, P.J.; Boels, I.C.; Kleerebezem, M.; Hugenholtz, J. Regulation of Exopolysaccharide Production By Lactococcus lactis Subsp. Cremoris by the Sugar Source. Appl. Environ. Microbiol. 1999, 65, 5003-5008. [CrossRef]

75. Sengupta, D.; Datta, S.; Biswas, D. Towards a Better Production of Bacterial Exopolysaccharides by Controlling Genetic as Well as Physico-Chemical Parameters. Appl. Microbiol. Bio. 2018, 102, 1587-1598. [CrossRef]

76. Mozzi, F.; Rollan, G.; de Giori, G.S.; de Valdez, G.F. Effect of Galactose and Glucose on the Exopolysaccharide Production and the Activities of Biosynthetic Enzymes in Lactobacillus Casei CRL 87. J. Appl. Microbiol. 2001, 91, 160-167. [CrossRef] [PubMed]

77. Denger, K.; Weiss, M.; Felux, A.-K.; Schneider, A.; Mayer, C.; Spiteller, D.; Huhn, T.; Cook, A.M.; Schleheck, D. Sulphoglycolysis in Escherichia coli K-12 Closes a Gap in the Biogeochemical Sulphur Cycle. Nature 2014, 507, 114-117. [CrossRef]

78. Speciale, G.; Jin, Y.; Davies, G.J.; Williams, S.J.; Goddard-Borger, E.D. YihQ Is a Sulfoquinovosidase That Cleaves Sulfoquinovosyl Diacylglyceride Sulfolipids. Nat. Chem. Biol. 2016, 12, 215-217. [CrossRef] [PubMed]

79. Sacoman, J.L.; Badish, L.N.; Sharkey, T.D.; Hollingsworth, R.I. The Metabolic and Biochemical Impact of Glucose 6-Sulfonate (Sulfoquinovose), a Dietary Sugar, on Carbohydrate Metabolism. Carbohyd. Res. 2012, 362, 21-29. [CrossRef] [PubMed]

80. Barak, J.D.; Jahn, C.E.; Gibson, D.L.; Charkowski, A.O. The Role of Cellulose and O-Antigen Capsule in the Colonization of Plants by Salmonella enterica. Mol. Plant-Microbe Interact. 2007, 20, 1083-1091. [CrossRef] [PubMed]

81. Marvasi, M.; Cox, C.E.; Xu, Y.; Noel, J.T.; Giovannoni, J.J.; Teplitski, M. Differential Regulation of Salmonella Typhimurium Genes Involved in O-Antigen Capsule Production and Their Role in Persistence within Tomato Fruit. Mol. Plant-Microbe Interact. 2013, 26, 793-800. [CrossRef]

82. Crawford, R.W.; Gibson, D.L.; Kay, W.W.; Gunn, J.S. Identification of a Bile-Induced Exopolysaccharide Required for Salmonella Biofilm Formation on Gallstone Surfaces. Infect. Immun. 2008, 76, 5341-5349. [CrossRef] [PubMed]

83. Peterson, A.A.; McGroarty, E.J. High-Molecular-Weight Components in Lipopolysaccharides of Salmonella Typhimurium, Salmonella Minnesota, and Escherichia coli. J. Bacteriol. 1985, 162, 738-745. [CrossRef] [PubMed]

84. Murray, G.L.; Attridge, S.R.; Morona, R. Regulation of Salmonella Typhimurium Lipopolysaccharide O Antigen Chain Length Is Required for Virulence; Identification of FepE as a Second Wzz: LPS Chain Length Regulation in S. Typhimurium. Mol. Microbiol. 2003, 47, 1395-1406. [CrossRef] [PubMed] 